\title{
Computer-Based Approaches for Determining the Pharmacological Profile of 5-(3-Nitro-Arylidene)- Thiazolidine-2,4-Dione
}

\author{
Shahenur Alam Sakib 1,2, Mohammad Forhad Khan 2,3, Mohammad Arman 2, Faisal Bin Kader 2, \\ Mohammad Omar Faruk 2, Shaifullah Mansur Tanzil 2, Tapas Debnath ${ }^{1}$, Md. Areeful Haque 2,4,* (D), \\ Simone Brogi ${ }^{\text {,* (D) }}$
}

1 Department of Theoretical and Computational Chemistry, University of Dhaka, Dhaka 1000, Bangladesh; sakibhasaniiuc@gmail.com (S.A.S.); debnath@du.ac.bd (T.D.);

2 Department of Pharmacy, International Islamic University Chittagong, Chittagong-4318, Bangladesh; forhadkhaniiuc@gmail.com (M.F.K.); mohammadarman7787@gmail.com (M.A.); faisal.thepharmacist@gmail.com (F.B.K.); umarfaruk11193@gmail.com (M.O.F.); shaifullahmansur51@gmail.com (S.M.T.);

3 Department of Pharmacy, State University of Bangl;adesh, Dhaka-1205, Bangladesh; forhadkhaniiuc@gmail.com (M.F.K.);

4 Drug \& Herbal Research Centre, Faculty of Pharmacy, Universiti Kebangsaan Malaysia, 50300 Kuala Lumpur, Malaysia; areeful@gmail.com or areeful@iiuc.ac.bd (M.A.H.);

5 Department of Pharmacy, University of Pisa, via Bonanno, 6, I-56126, Pisa, Italy.; simone.brogi@ unipi.it (S.B.);

* Correspondence: areeful@gmail.com, areeful@iiuc.ac.bd (M.A.H.); simone.brogi@unipi.it (S.B.); Scopus Author ID 57193254909 (M.A.H.) 57208811281 (S.B.)

Received: 21.01.2021; Revised: 18.02.2021; Accepted: 23.02.2021; Published: 1.03.2021

Abstract: The development of novel and safe compounds is a challenging task in the drug discovery trajectory. Accordingly, the individuation of promising core molecules with biological activities could pave the way to develop effective drugs to treat a given disease. The use of a computational approach can reduce the time for identifying promising core molecules characterizing their potential pharmacological profile and providing hints for the synthesis of novel derivatives with increased predicted pharmacological activity. Following this strategy, starting from a core molecule thiazolidine2,4-dione, the derivative of 5-(3-nitro-arylidene)-thiazolidine-2,4-dione was synthesized to investigate the biological and pharmacological potential. An extensive computational investigation was performed employing $a b$ initio calculations by using Density Functional Theory (DFT), and subsequent in silico studies were accomplished by molecular docking calculation. The structures 5-(3-nitro-arylidene)thiazolidine-2,4-dione were fully optimized using multiparametric DFT methods were calculated at the B3LYP/6-31+G $(d, p)$ level basis set. Besides gaining insights into the potential pharmacological profile of the selected derivative, molecular docking against some selected drug targets, ADME, and PASS prediction were performed. According to charges and molecular electrostatic potential (MESP) calculation, the $\mathrm{N}-\mathrm{H}$ region could offer promising active site interactions for protein binding. Furthermore, Homo-Lumo and global reactivity values indicate a good profile for the selected compound, and UV-Vis provides further insights about its properties, potentially helpful for further experimental analysis. Notably, the in silico investigation indicated that EGFR and ORF2 enzymes could represent the selected drug-like compound's possible targets. Conclusively, the proposed computational approach demonstrated that it is possible to evaluate a proposed compound's bioactivity profile. We characterized 5-(3-nitro-arylidene)-thiazolidine-2,4-dione derivative, suggesting it as a good starting point for developing interesting hit compounds with a relevant pharmacological profile.

Keywords: FT-IR; NBO; UV-Vis spectroscopy; computational chemistry; computational pharmacology; HOMO-LUMO; MESP; ${ }^{1} \mathrm{H}$ and ${ }^{13} \mathrm{C}$ NMR.

(C) 2021 by the authors. This article is an open-access article distributed under the terms and conditions of the Creative Commons Attribution (CC BY) license (https://creativecommons.org/licenses/by/4.0/). 


\section{Introduction}

Chemical entities enclosing heterocyclic ring structures and nitrogen and sulfur atoms represent valuable compounds, particularly in medicinal chemistry. In fact, for example, sulfur atoms in drug candidates present as sulfide or disulfide confer significant metabolic stability to derivatives containing these moieties [1]. Thiazolidine-2,4-dione represents a key nucleus used for developing several thiazolidine derivatives with promising pharmacological properties. Thiazolidine-2,4-dione consists of a 5-member ring. It could usually comprise sulfur and nitrogen atoms in positions 2 and 4 . In contrast, in positions 3 and 5 can be found a carbonyl function. Different substituents are usually located in position 1 and/or position 4 (Figure 1) [2].

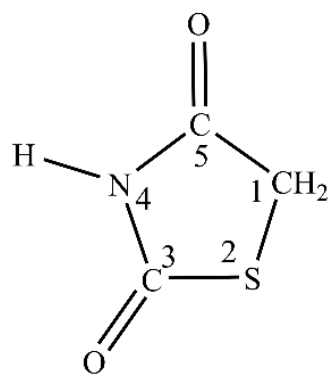

Figure 1. Chemical structure of the selected nucleus.

Currently, heterocyclic compounds containing thiazolidine-2,4-dione continue to attract scientists since these molecules are considered for developing novel compounds possessing appropriate pharmacological profiles [3]. The promising activity showed by compounds containing thiazolidine-2,4-dione nucleus suggested that this moiety is particularly relevant for developing innovative drug candidates against several disorders [4]. Furthermore, molecules containing the mentioned nucleus demonstrated their inhibitory effects against aldose-reductase enzyme and were found to possess a significant anti-oxidant profile able to counteract the oxidative stress related to diabetic complications and other diseases [5].

According to the literature reports, when the substituents and their respective positions on the selected nucleus change, the resulting compounds produce different biological activities. From this perspective, applying classical medicinal chemistry approaches is crucial to discover and rationally design novel bioactive compounds improving the pharmacological potential of given nuclei [6]. To this end, coupling classical medicinal chemistry approaches with computational strategies allows determining which arrangements and decorations of an appropriate nucleus are suitable for improving the affinity of resulting chemical entities for a selected active site of a given target [7,8]. Molecular modeling software offers several benefits for processing chemical information, with the possibility to calculate several molecular descriptors relevant for the rational design and discovery of novel drug-like derivatives. The calculation of a given chemical entity's pharmacokinetic profile includes ADME/T (absorption, distribution, metabolism, excretion, and toxicity), bioavailability, water-solubility, blood-brain barrier penetration, intestinal absorption, etc. [9-12]. Remarkably, to date, no comprehensive investigation, combining theoretical and experimental studies, regarding the mentioned thiazolidine-2,4-dione nucleus has been performed. Accordingly, because of the significance of the thiazolidine-2,4-dione core, a compound containing this nucleus, 5-(3-nitro-arylidene)thiazolidine-2,4-dione (53NAT24D), has been selected for the first comprehensive computational investigation about its potential pharmacological profile. 


\section{Materials and Methods}

\subsection{Density Functional Theory (DFT).}

Quantum chemical DFT analysis for 53NAT24D was completed using Gaussian 16 program package, running on Intel Core i7 Processor (8M Cache@4.60 GHz), via gauss view 6.0.10 molecular visualization software $[13,14]$. The investigation was done at the DFT/B3LYP/6-31+G(d,p) level of theory [15]. The absence of any imaginary frequency indicated that 53NAT24D was fully optimized. The geometrical parameters (bond lengths, bond angles, torsion angle) of 53NAT24D were acquired employing an identical level of theory by gradient geometry optimization. The electronic properties, including point group, dipole moment, charges, molecular electrostatic potential, Еномо, ELUMо, HOMO-LUMO energy gap, global reactivity descriptors were calculated considering the optimized structure in the gas phase. For UV-Vis computation, the maximum absorption wavelengths $\left(\lambda_{\max }\right)$ and oscillator strength were acquired by Time-dependent DFT (TD-DFT) method. Natural bond orbital (NBO) investigation regarding 53NAT24D was performed to understand intermolecular delocalization and hyperconjugation using the same method and basis set. Vibrational frequency calculations were completed to establish the critical points' nature; a suitable scaling number (0.964) was multiplied with calculated vibrational frequencies to match experimental frequencies better [16]. Furthermore, FT-NMR prediction, the optimized structure in $\mathrm{CHCl}_{3}$ solvent ( $\varepsilon=4.7113$ ) by IEFPCM (integral equation formation polarizable continuum model), and the ${ }^{1} \mathrm{H}$ and ${ }^{1} \mathrm{C}$ chemical shifts of 53NAT24D was found employing the gauge-invariant atomic orbital (GIAO) technique. Determination of non-covalent interactions (NCI) with water was carried out by analyzing the wave function for the optimized structure of 53NAT24D using the Multiwfn software package [17].

\subsection{Global descriptors equations.}

Koopmans' theorem [18] described (I) and (A) values which correlated with the frontier orbitals by the relation: ionization potential $(\mathrm{I})=-\mathrm{E}_{\text {HOMO }}$ and electronic affinity $(\mathrm{A})=-\mathrm{ELUMO}_{\mathrm{L}}$; where $\mathrm{I}$ is referred to the amount of energy required to eradicate an electron from a compound (i.e., high ionization potential specifies great stability and chemical inertness), A is described as the quantity of released energy when one electron is added to a neutral compound (i.e., high electronic affinity for a molecule highlights a tendency to take electrons effortlessly).

According to the theorem, some global reactivity descriptors as: electronegativity $(\chi)$, chemical potential $(\mu)$, hardness $(\eta)$, softness $(S)$, and electrophilicity index $(\omega)$ have been introduced by quantum chemical equations such as, $\chi=(\mathrm{I}+\mathrm{A}) / 2 ; \mu=-(\mathrm{I}+\mathrm{A}) / 2 ; \eta=(\mathrm{I}-\mathrm{A}) / 2$; $\mathrm{S}=1 / \eta ; \omega=\mu^{2} / 2 \eta[19-23]$.

\subsubsection{Non-covalent interaction equation.}

The reduced density gradient (RDG) can provide information about intramolecular and intermolecular interactions to distinguish interaction type and strength. The non-covalent interaction (NCI) analysis arranges for an index centered on the electron density, enabling NCI identification [24]. The NCI index is founded on a 2D plot of the reduced density gradient (RDG), specified by the letter $s$, and the electron density, $\rho$, is

$$
\operatorname{RDG}(\mathrm{s})=\frac{1}{2\left(3 \pi^{2}\right)^{1 / 3}} \frac{\left[\nabla_{p}(r)\right]}{\rho(r)^{4 / 3}}
$$


When a weak inter- or intramolecular interaction is existent, a relevant change in the reduced gradient among the interacting atoms is present, generating critical density points among interacting fragments. Additionally, based on Bader's Atoms in Molecules principle [25], the second-largest eigenvalue $\lambda_{2}$ of Hessian matrix of electron density and $\rho(r)$ are obtained from the equation:

$$
\Omega(r)=\operatorname{sign}\left(\lambda_{2}(r)\right) \rho(r)
$$

\subsection{ADME and PASS analysis.}

The drug-like profile of 53NAT24D was investigated by calculating ADME/T properties based on assessing Lipinski's 'Rule of Five', calculating different molecular descriptors including topological surface area, number of $\mathrm{H}$-bond donors, and acceptors, partition coefficient.[26] The ADME/T properties were evaluated by SwissADME (http://www.swissadme.ch/) and QikProp (Schrödinger v11.1) [27]. Moreover, the potential biological activity of 53NAT24D regarding anti-inflammatory, anticonvulsant, antitumor, antimicrobial, anti-viral, and other ones was evaluated using the web-server PASS (Prediction of $\begin{array}{lllll}\text { Activity Spectra } & \text { for } & \text { Substances) } & \text { (PASSonline }\end{array}$ http://www.pharmaexpert.ru/PASSonline/predict.php) [28]. The outcome listed possible activities of the selected molecule reporting the probability to be active (Pa) and inactive $(\mathrm{Pi})$ with respect to the potential biological activities selected for the analysis [12].

\subsection{Ligand and protein preparation.}

The compound 53NAT24D was built employing Gauss view 06 [29]. Energy minimization was performed by using the MO-G program implemented in Gauss view. This method calculates and minimizes energy associated with the heat of formation. After this computational analysis, the compound 53NAT24D was treated by LigPrep software. The 3D structure of the enzymes related to the potential biological activities highlighted by the online tool, namely PASS, was obtained in PDB format from the protein data bank website. In particular, we considered: human mitochondrial branched-chain aminotransferase (BCATm) (PDB ID: 2A1H), Human Carbonic Anhydrase II (PDB ID: 3OYS), Human Adenosine Kinase (PDB ID: 2I6B), SARS-COV-2 main protease (PDB ID: 5RGX), Human Coronavirus PapainLike Protease (PDB ID: 4OW0), HCV NS5B RNA-dependent RNA polymerase (4KHR), human MR1 - Major histocompatibility complex class I-related gene protein- (PDB ID: 5U1R), prostaglandin D2 11-ketoreductase (AKR1C3) (PDB ID: 1S1P/1S1R), Epidermal Growth Factor Receptor (EGFR) tyrosine kinase domain (PDB ID: 1M17), isocitrate dehydrogenase 1 (IDH1 with mutation R132H) (PDB ID: 4UMX), human pyruvate dehydrogenase (PDB ID: 3EXE), beta-ketoacyl-ACP synthase-III (PDB ID: 1HNJ), E. coli FolC (PDB ID: 1W7K), and ORF2 aromatic prenyltransferase (PDB ID: 1ZB6) [30]. Afterward, protein structures were treated with protein preparation wizard in Schrödinger Drug Discovery suite-Maestro version 11.1 for obtaining reasonable starting structures used in molecular docking calculations [31$38]$.

\subsection{Glide standard precision (SP) ligand docking.}

The Glide program implemented in Schrödinger suite release 2018 was employed for molecular docking investigation as previously reported [39-46] for determining the docking scores of desired complexes. Regarding this work, a flexible ligand docking method was 
selected in the Glide program. The grid for each selected drug target was generated, considered the crystallized inhibitor. No additional constraints were specified during the calculations. For the post-docking minimization process, the force field OPLS 2005 was used.

\section{Results and Discussion}

\subsection{Molecular geometry.}

The optimized 53NAT24D obtained by ab initio investigation is depicted in Figure 2. Regarding the structural side, the selected compound belongs to $\mathrm{C} 1$ point group symmetry. Therefore, all the calculated frequencies change to the same asymmetry species. Due to the lack of experimentally solved structures, it is crucial to perform an inclusive conformational analysis of a given molecule to establish the most stable conformation of the molecule. Starting from DFT calculations, the geometry optimization energy of 53NAT24D with dipole moment and polarizability was -1193.23454 a.u., 5.020 Debye, and 183.87 a.u., respectively.

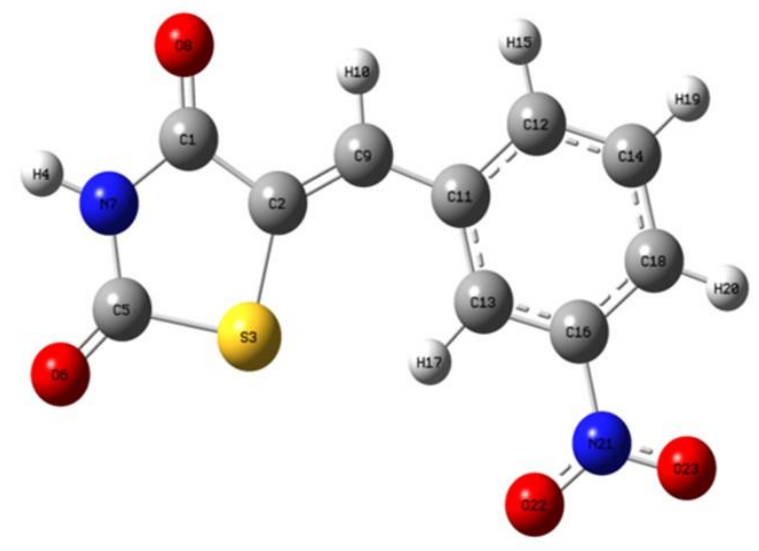

Figure 2. Optimized structure of 53NAT24D.

\subsection{Geometrical parameters.}

The geometrical parameters (bond length, bond angle, dihedral angle) of 53NAT24D derived from DFT calculations are included in Table 1.

Table 1. Geometrical parameters (bond length (BL), bond angle (BA), and dihedral angle (DA)) of 53NAT24D

\begin{tabular}{|c|c|c|c|c|c|}
\hline Atoms & BL $(\AA)$ & Atoms & BA (Å) & Atoms & DA (̊̊) \\
\hline $\mathrm{C}_{2}=\mathrm{C}_{9}$ & 1.351 & $\mathrm{C}_{2}-\mathrm{C}_{9}-\mathrm{C}_{11}$ & 131.59 & $\mathrm{H}_{10}-\mathrm{C}_{9}-\mathrm{C}_{2}-\mathrm{C}_{1}$ & 0 \\
\hline $\mathrm{C}_{9}-\mathrm{C}_{11}$ & 1.458 & $\mathrm{H}_{10}-\mathrm{C}_{9}-\mathrm{C}_{2}$ & 113.09 & $\mathrm{H}_{10}-\mathrm{C}_{9}-\mathrm{C}_{11}-\mathrm{C}_{12}$ & 0.003 \\
\hline $\mathrm{C}_{9}-\mathrm{C}_{10}$ & 1.088 & $\mathrm{H}_{10}-\mathrm{C}_{9}-\mathrm{C}_{11}$ & 115.30 & $\mathrm{C}_{9}-\mathrm{C}_{2}-\mathrm{C}_{1}-\mathrm{O}_{8}$ & 0.001 \\
\hline $\mathrm{C}_{11}-\mathrm{C}_{13}$ & 1.407 & $\mathrm{C}_{2}-\mathrm{C}_{1}-\mathrm{O}_{8}$ & 126.51 & $\mathrm{C}_{9}-\mathrm{C}_{11}-\mathrm{C}_{12}-\mathrm{H}_{15}$ & 0 \\
\hline $\mathrm{C}_{13}-\mathrm{C}_{16}$ & 1.390 & $\mathrm{C}_{11}-\mathrm{C}_{12}-\mathrm{H}_{15}$ & 118.89 & $\mathrm{C}_{9}-\mathrm{C}_{11}-\mathrm{C}_{13}-\mathrm{H}_{17}$ & 0 \\
\hline $\mathrm{C}_{11}-\mathrm{C}_{17}$ & 1.081 & $\mathrm{C}_{11}-\mathrm{C}_{12}-\mathrm{H}_{14}$ & 121.58 & $\mathrm{C}_{9}-\mathrm{C}_{2}-\mathrm{S}_{3}-\mathrm{C}_{5}$ & 179.98 \\
\hline $\mathrm{C}_{18}-\mathrm{C}_{20}$ & 1.082 & $\mathrm{C}_{11}-\mathrm{C}_{13}-\mathrm{C}_{16}$ & 119.27 & C2-S3-C5-O6 & 180 \\
\hline $\mathrm{C}_{16}-\mathrm{N}_{21}$ & 1.478 & $\mathrm{C}_{11}-\mathrm{C}_{13}-\mathrm{H}_{17}$ & 122.63 & $\mathrm{C}_{11}-\mathrm{C}_{13}-\mathrm{C}_{16}-\mathrm{N}_{21}$ & 180 \\
\hline $\mathrm{N}_{21}=\mathrm{O}_{22}$ & 1.230 & $\mathrm{C}_{13}-\mathrm{C}_{16}-\mathrm{N}_{21}$ & 118.43 & $\mathrm{C}_{13}-\mathrm{C}_{16}-\mathrm{N}_{21}-\mathrm{O}_{22}$ & 0.015 \\
\hline $\mathrm{C}_{1}-\mathrm{C}_{2}$ & 1.497 & $\mathrm{C}_{16}-\mathrm{N}_{21}-\mathrm{O}_{22}$ & 117.72 & $\mathrm{~N}_{21}-\mathrm{C}_{16}-\mathrm{C}_{18}-\mathrm{H}_{20}$ & 0 \\
\hline $\mathrm{C}_{1}=\mathrm{O}_{8}$ & 1.217 & $\mathrm{O}_{23}-\mathrm{N}_{21}-\mathrm{O}_{22}$ & 124.73 & $\mathrm{C}_{20}-\mathrm{C}_{18}-\mathrm{C}_{14}-\mathrm{H}_{19}$ & 0 \\
\hline $\mathrm{C}_{1}-\mathrm{N}_{7}$ & 1.391 & $\mathrm{C}_{14}-\mathrm{C}_{18}-\mathrm{H}_{20}$ & 122.10 & $\mathrm{C}_{11}-\mathrm{C}_{13}-\mathrm{C}_{16}-\mathrm{C}_{18}$ & 0 \\
\hline $\mathrm{N}_{7}-\mathrm{H}_{4}$ & 1.013 & $\mathrm{C}_{9}-\mathrm{C}_{2}-\mathrm{S}_{3}$ & 130.22 & $\mathrm{O}_{8}-\mathrm{C}_{1}-\mathrm{N}_{7}-\mathrm{H}_{4}$ & 0.005 \\
\hline $\mathrm{N}_{7}-\mathrm{C}_{5}$ & 1.383 & $\mathrm{C}_{1}-\mathrm{C}_{2}-\mathrm{S}_{3}$ & 110.60 & $\mathrm{H}_{4}-\mathrm{N}_{7}-\mathrm{C}_{5}-\mathrm{O}_{6}$ & 0.012 \\
\hline $\mathrm{C}_{5}=\mathrm{O}_{8}$ & 1.206 & $\mathrm{C}_{2}-\mathrm{C}_{1}-\mathrm{N}_{7}$ & 109.65 & $\mathrm{C}_{11}-\mathrm{C}_{9}-\mathrm{C}_{2}-\mathrm{S}_{3}$ & 0 \\
\hline $\mathrm{C}_{5}-\mathrm{O}_{6}$ & 1.206 & $\mathrm{O}_{8}-\mathrm{C}_{1}-\mathrm{N}_{7}$ & 123.83 & $\mathrm{H}_{10}-\mathrm{C}_{9}-\mathrm{C}_{11}-\mathrm{C}_{13}$ & 180 \\
\hline $\mathrm{C}_{5}-\mathrm{S}_{3}$ & 1.813 & $\mathrm{C}_{1}-\mathrm{N}_{7}-\mathrm{H}_{4}$ & 120.90 & $\mathrm{H}_{10}-\mathrm{C}_{9}-\mathrm{C}_{2}-\mathrm{S}_{3}$ & 180 \\
\hline
\end{tabular}




\begin{tabular}{|c|c|c|c|c|c|}
\hline Atoms & BL (̊̊) & Atoms & BA $(\AA)$ & Atoms & DA (̊̊) \\
\hline $\mathrm{C}_{2}-\mathrm{S}_{3}$ & 1.773 & $\mathrm{~N}_{7}-\mathrm{H}_{4}-\mathrm{C}_{5}$ & 120 & $\mathrm{C}_{9}-\mathrm{C}_{11}-\mathrm{C}_{13}-\mathrm{C}_{16}$ & 180 \\
\hline $\mathrm{C}_{13}-\mathrm{H}_{17}$ & 1.081 & $\mathrm{~N}_{7}-\mathrm{C}_{5}-\mathrm{O}_{6}$ & 126.48 & $\mathrm{C}_{9}-\mathrm{C}_{11}-\mathrm{C}_{13}-\mathrm{H}_{17}$ & 0 \\
\hline $\mathrm{N}_{21}-\mathrm{O}_{23}$ & 1.230 & $\mathrm{~S}_{3}-\mathrm{C}_{5}-\mathrm{O}_{6}$ & 124.63 & & \\
\hline \multirow[t]{5}{*}{$\mathrm{N}_{21}-\mathrm{C}_{16}$} & 1.478 & $\mathrm{C}_{9}-\mathrm{C}_{11}-\mathrm{C}_{12}$ & 117.5 & & \\
\hline & & $\mathrm{C}_{9}-\mathrm{C}_{11}-\mathrm{C}_{13}$ & 124.4 & & \\
\hline & & $\mathrm{C}_{9}-\mathrm{C}_{2}-\mathrm{C}_{1}$ & 119.1 & & \\
\hline & & $\mathrm{N}_{7}-\mathrm{C}_{5}-\mathrm{S}_{3}$ & 108.87 & & \\
\hline & & $\mathrm{C}_{2}-\mathrm{S}_{3}-\mathrm{C}_{5}$ & 91.78 & & \\
\hline
\end{tabular}

The calculated bond lengths regarding the $\mathrm{C}-\mathrm{C}$ and $\mathrm{C}-\mathrm{H}$ belonging to the aromatic ring at different positions ranging from $1.497 \AA \sim 1.088 \AA$ and $1.081 \AA \sim 1.098 \AA$, respectively. The $\mathrm{C}-\mathrm{N}$ bond length value of $1.391 \AA$ in the thiazolidine scaffold appears to be shorter than the classical C-N bond (1.417 $\AA$ ), while the $\mathrm{C}_{16}-\mathrm{N}_{21}$ bond length related to the aromatic ring is 1.478. In the present investigation, the optimized bond length of $\mathrm{C}_{5}-\mathrm{S}_{3}$ was $1.813 \AA$ and for $\mathrm{N}_{7}$ $\mathrm{H}_{4}$ was $1.013 \AA$, which are potential moieties for introducing in the thiazolidine ring electrondonating and withdrawing substituents. As for the $\mathrm{H}_{10}-\mathrm{C}_{9}-\mathrm{C}_{2}, \mathrm{H}_{10}-\mathrm{C}_{9}-\mathrm{C}_{11}, \mathrm{C}_{2}-\mathrm{C}_{9}-\mathrm{C}_{11}, \mathrm{C}_{9}-\mathrm{C}_{2}-\mathrm{C}_{1}$, $\mathrm{C}_{9}-\mathrm{C}_{2}-\mathrm{S}_{3}, \mathrm{C}_{9}-\mathrm{C}_{11}-\mathrm{C}_{12}$, and $\mathrm{C}_{9}-\mathrm{C}_{11}-\mathrm{C}_{13}$ bond angles of 53NAT24D were $113.09 \AA$ 131.59 $\AA$, $119.17 \AA, 130.22 \AA, 117.56 \AA$, and $124.41 \AA$, respectively (i.e., connection point thiazolidine-aromatic ring). It was clearly represented that the angle at the point of substitution $\mathrm{O}_{22}-\mathrm{N}_{21}-\mathrm{O}_{23}$ for 53NAT24D was $124.73 \AA$. The minor dissimilarities concerning theoretical and experimental data of bond lengths and angles could be ascribable to intermolecular hydrogen bonds and different conditions; the experimental data were acquired using solidphase while the computational ones were obtained in the gaseous phase. Moreover, in general, regarding the thiazolidine-2,4-dione containing compounds, it was observed that just one degree of freedom is significant in this investigation $\left(\mathrm{C}_{12}-\mathrm{C}_{11}-\mathrm{C}_{9}-\mathrm{H}_{10}\right)$. From our in silico results, the dihedral angle of $\mathrm{C}_{12}-\mathrm{C}_{11}-\mathrm{C}_{9}-\mathrm{H}_{10}$ of 53NAT24D was $0^{\circ}$. Additionally, bonds and dihedral angles were reported in Table 1 with associated atom's positions. The quantum chemical geometrical process data may be useful for the additional experimental investigation to highlight a correlation between computational and experimental values.

\subsection{Thermodynamics and molecular parameters.}

The calculated thermodynamics and molecular features of 53NAT24D were displayed in Table 2. The overall energy of a compound derives from a sum of electronic, vibrational, rotational, and translational energies $E=\left(E_{e}+E_{v}+E_{r}+E_{t}\right)$.

Table 2. Calculated thermodynamics and molecular features regarding 53NAT24D.

\begin{tabular}{l|l} 
Parameters & DFT/6-31+G(d,p) \\
\hline Self-consistent field energy (a.u.) & -1193.175364 \\
\hline Zero-point vibrational energy(j/mol) & 402675.1 \\
\hline Zero-point vibrational energy(kcal/mol) & 96.24167 \\
\hline Rotational temperatures (K) & 0.03896 \\
\hline A & 0.01106 \\
\hline B & 0.00862 \\
\hline C & 0.81188 \\
\hline Rotational constant $(\mathrm{GHz})$ & 0.23055 \\
\hline A & 0.17956 \\
\hline C & 0.889
\end{tabular}




\begin{tabular}{l|l} 
Parameters & DFT/6-31+G(d,p) \\
\hline Rotational & 0.889 \\
\hline Vibrational & 103.281 \\
\hline Enthalpy/Molar capacity at constant volume $=52.467 \mathrm{cal} / \mathrm{mol}-\mathrm{k}$ \\
\hline Translational & 2.981 \\
\hline Rotational & 2.981 \\
\hline Vibrational & 46.505 \\
\hline Entropy total=123.483 cal/mol-k & 42.449 \\
\hline Translational & 33.525 \\
\hline Rotational & 47.509 \\
\hline Vibrational & 0 \\
\hline Dipole moment=5.02037 Debye & 0 \\
\hline$\mu_{\mathrm{x}}$ & 5.02037 \\
\hline$\mu_{\mathrm{y}}$ & \\
\hline$\mu_{\mathrm{z}}$ & 0.153371 \\
\hline Thermal properties (Hartree/particle) & 0.167422 \\
\hline Zero-point correction & 0.168366 \\
\hline Thermal correction to the energy & 0.109695 \\
\hline Thermal correction to enthalpy & -1193.081173 \\
\hline Thermal correction to Gibbs free energy & -1193.067122 \\
\hline Sum of electronic and zero-point energy & -1193.066177 \\
\hline Sum of electronic and thermal energies & -1193.124848 \\
\hline Sum of electronic and thermal enthalpies & \\
\hline Sum of electronic and thermal free energies & \\
\hline
\end{tabular}

The thermodynamic and molecular parameters including zero-point vibration energies (ZPVE), heat capacity $\left(\mathrm{C}_{\mathrm{V}}\right)$, thermal energy $(\mathrm{E})$, enthalpy $(\mathrm{H})$, entropy $(\mathrm{S})$, rotational temperature $(\mathrm{T})$, dipole moment $(\mu)$, rotational constants $(\mathrm{GHz})$, and thermal properties for 53NAT24D were also calculated employing DFT/B3LYP/6-31+G(d,p) at $298.15 \mathrm{~K}$ (room temperature) and $1 \mathrm{~atm}$ of pressure. The thermal correction was estimated as the sum of ZPVE and $\mathrm{E}$ for molecular translational, rotational, and vibrational energies. The term $\mathrm{H}$ was found by adding RT to the electronic and thermal energies. This information and Gibb's free energy term were acquired from the Gaussian output file in Hartrees and transformed to $\mathrm{kJ} / \mathrm{mol}$ ( 1 Hartree $=2625.50 \mathrm{~kJ} / \mathrm{mol}$ ). Based on the mentioned investigation results, 53NAT24D showed $\mathrm{E}, \mathrm{H}, \mathrm{S}$, and $\mu$ values of $105.059 \mathrm{kcal} / \mathrm{mol}, 52.467 \mathrm{cal} / \mathrm{mol}-\mathrm{k}, 123.483 \mathrm{cal} / \mathrm{mol}-\mathrm{k}$, and 5.020 debyes respectively. Also, thermal properties (Hartree/particle), rotational temperatures, and rotational constants were reported in Table 2. While the final temperature of 53NAT24D is higher than its initial temperature, it shows a positive thermal energy value. A positive $\mathrm{H}$ value denotes the addition of energy from the reaction or the surroundings, resulting in an endothermic reaction. A positive value of $S$ changes describes an increase in $S$ while the system becomes more random. The Law of Disorder, also known as the second law of thermodynamics, stated that natural systems increase their $\mathrm{S}$. In fact, $\mu$ indicates the charge separation in a given compound. The larger the difference in electronegativities of bonded atoms, the larger $\mu$.

\subsection{Charges and MESP calculation.}

Atomic charges calculated for a selected compound are usually employed in chemistry for describing the charge transfer and the electronegativity term. The evaluation of atomic charges is crucial for applying quantum chemical calculations to molecular systems. In the presented work, we noted that atomic charges influenced some molecular properties (i.e., 
electronic structure, $\mu$ ) of 53NAT24D. The calculations of Mulliken [47] and NBO [48] charges of 53NAT24D were presented in Table 3.

As reported in the mentioned table, it is possible to observe that the highest positive value in Mulliken charges was 0.460 a.u. lodged on the $\mathrm{C}_{9}$ atom, while in NBO charges, the highest positive value was 0.668 a.u. on the $\mathrm{C}_{1}$ atom of 53NAT24D. Besides, regarding the Mulliken charges, we observed that the highest negative value of -1.077 a.u. was located on the $\mathrm{C}_{12}$ atom of the aromatic ring, wherein NBO charges provide the highest negative value of -0.681 a.u. on the $\mathrm{N}_{7}$ atom of 53NAT24D. From this calculation, the highest positive and negative value of Mulliken and NBO charge of atoms was not agreed to each other due to the method's different developmental way.

Table 3. Mulliken atomic and NBO charges in the gas phase of 53NAT24D.

\begin{tabular}{|c|c|c|}
\hline \multirow[t]{2}{*}{ Atom } & \multicolumn{2}{|c|}{ Atomic charges (53NAT24D) } \\
\hline & Mulliken charges & NBO charges \\
\hline $\mathbf{C}_{1}$ & 0.440 & 0.668 \\
\hline $\mathbf{C}_{2}$ & 0.118 & -0.307 \\
\hline $\mathbf{S}_{3}$ & 0.374 & 0.327 \\
\hline $\mathrm{H}_{4}$ & 0.350 & 0.469 \\
\hline $\mathrm{C}_{5}$ & 0.092 & 0.530 \\
\hline $\mathbf{O}_{6}$ & -0.421 & -0.551 \\
\hline $\mathbf{N}_{7}$ & -0.327 & -0.681 \\
\hline $\mathbf{O s}$ & -0.488 & -0.570 \\
\hline $\mathbf{C}_{9}$ & 0.460 & -0.160 \\
\hline $\mathbf{H}_{10}$ & 0.165 & 0.277 \\
\hline $\mathbf{C}_{11}$ & -0.061 & -0.094 \\
\hline $\mathbf{C}_{12}$ & -1.077 & -0.172 \\
\hline $\mathbf{C}_{13}$ & -0.077 & -0.187 \\
\hline $\mathrm{C}_{14}$ & -0.186 & -0.237 \\
\hline $\mathbf{H}_{15}$ & 0.144 & 0.256 \\
\hline $\mathbf{C}_{16}$ & 0.055 & 0.066 \\
\hline $\mathbf{H}_{17}$ & 0.152 & 0.274 \\
\hline $\mathrm{C}_{18}$ & 0.288 & -0.204 \\
\hline $\mathrm{H}_{19}$ & 0.147 & 0.262 \\
\hline $\mathbf{H}_{20}$ & 0.175 & 0.285 \\
\hline $\mathbf{N}_{21}$ & -0.328 & 0.495 \\
\hline $\mathrm{O}_{22}$ & -0.004 & -0.372 \\
\hline $\mathrm{O}_{23}$ & 0.007 & -0.374 \\
\hline
\end{tabular}

MESP is a significant parameter to understand the molecular interactions regarding a given compound. It is widely used to interpret and predict the reactive deeds of numerous chemical systems involved in electrophilic and nucleophilic reactions [49]. To evaluate possible reactive sites involved in electrophilic and nucleophilic attack regarding 53NAT24D, MESP and surface contours were plotted, employing the Gauss-view program (Figure 3). The classical colors scheme regarding the MESP surface can be divided as follows: the red colored moieties mean the electron-rich areas (negative electrostatic potential), the blue colored moieties mean the electron-deficient parts (positive electrostatic potential), while the light blue colored regions mean the slightly electron-deficient areas, the yellow-colored moieties signify the marginally electron-rich portions, and the green-colored moieties denote regions of the molecule of zero potential. Besides, negative parts (red color) of MESP are associated with potential electrophilic reactivity, positive regions (blue color) are usually linked to nucleophilic reactivity. The picture also offers a pictorial illustration regarding the chemically active positions and the atoms' comparative reactivity. For 53NAT24D values range from $-9.874 \mathrm{e}^{-2}$ 
a.u. (deepest red) to $+9.874 \mathrm{e}^{-2}$ a.u. (deepest blue). Observing the map, 53NAT24D showed numerous negative portions related to $\mathrm{O}_{6}, \mathrm{O}_{8}$ atoms. In fact, the greatest positive value $(0.688$ a.u.) is linked to the $\mathrm{C}_{1}$ atom, while the most relevant negative values of -0.551 a.u. and -0.570 a.u. were found for $\mathrm{O}_{6}$ and $\mathrm{O}_{8}$ atoms, respectively. Accordingly, it would be possible that electrophiles could favorably attack $\mathrm{O}_{6}$ and $\mathrm{O}_{8}$ atoms of 53NAT24D. Instead, the deep blue portion of 53NAT24D on the N7-H4 moiety indicates that this region could probably be implicated in a nucleophilic attack within a given protein's binding site.

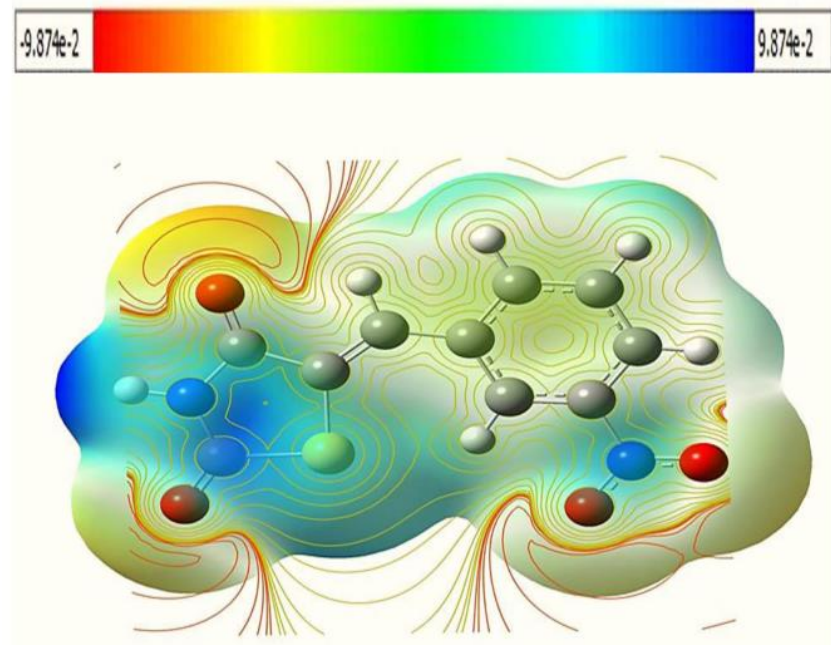

Figure 3. Calculated 3D surface mapped of electrostatic potential with surface contours for title compound in (a.u.), the electron density isosurface being 0.05 (a.u.).

\subsection{Natural bond orbital (NBO) analysis.}

The stabilizing interactions concerning filled and unoccupied orbitals and destabilizing interactions among filled orbitals can be achieved through the NBO analysis. This latter affords the most accurate 'natural Lewis structure' picture of $\mathrm{j}$ since all orbital data are mathematically selected for incorporating the highest probable percentage of the electron density. Delocalization of electron density among occupied Lewis-type (bond or lone pair) NBO orbitals and properly unoccupied (anti bond or Rydberg) non-Lewis NBO orbitals relates to stabilizing donor-acceptor interactions. Moreover, this approach allows obtaining information regarding interactions in both filled and virtual orbital spaces that might improve intra- and inter-molecular contacts analysis. The interactions due to electron delocalization are commonly studied by choosing several bonding and antibonding NBO's. For each donor NBO (i) and acceptor NBO $(j)$, the stabilization energy $E^{(2)}$ is related to $i \rightarrow j$ delocalization and calculated using the formula below:

$$
E^{2}=\Delta E_{i j}=q_{i} \frac{F(i, j)^{2}}{\varepsilon j-\varepsilon i}
$$

where, $q_{i}$ represents the donor orbital occupancy, $\varepsilon_{i}$ and $\varepsilon_{j}$ are diagonal elements, and $F(i, j)$ represents the off-diagonal NBO Fock matrix element. Regarding NBO analysis, big $\mathrm{E}^{(2)}$ value means an intensive interaction between electron-donors and electron-acceptors and bigger the entire system's range of conjugation [50]. NBO investigation was carried out for 53NAT24D, and the perturbation energies of key donor-acceptor interactions are reported in Table 4. The electron density of conjugated double and single bonds belonging to the benzene moiety reveals a robust delocalization of the electrons located inside the ring. The investigation of many donors and acceptors indicates that only three categories of donors (n, $\sigma$, and $\pi$ ), and two of 
acceptors $\left(\sigma^{*}\right.$ and $\left.\pi^{*}\right)$ are present. The NBO analysis unveils a huge interaction energy $\mathrm{E}^{(2)}$ between a donor bonding orbital and an antibonding acceptor orbital that could contribute to the delocalization compared with the typical Lewis structure. The interactions between the lone-pair $\left(\mathrm{O}_{23}\right)$ and the antibonding of $\left(\mathrm{N}_{21}=\mathrm{O}_{22}\right)$ show the largest $\mathrm{E}^{(2)}$ value $(162.33 \mathrm{kcal} / \mathrm{mol})$.

Table 4. Selected second-order perturbation theory analysis of the Fock matrix responsible for the main donor-

\begin{tabular}{|c|c|c|c|c|c|c|c|}
\hline Type & Donor (i) & $\begin{array}{c}\text { Occupancy } \\
\left({ }^{\mathrm{a} E D / e}\right)\end{array}$ & $\begin{array}{c}\text { Acceptor } \\
\text { (j) }\end{array}$ & $\begin{array}{c}\text { Occupancy } \\
\text { (ED/e) }\end{array}$ & ${ }^{\mathbf{b}} \mathbf{E}^{(2)}$ & $\begin{array}{c}\text { cE (j)- } \\
\mathbf{E}(\mathbf{i}) \\
\text { a.u. }\end{array}$ & $\begin{array}{c}\mathrm{d}^{\mathrm{d}} \mathbf{F}(\mathbf{i}, \\
\text { j) } \\
\text { a.u. }\end{array}$ \\
\hline \multirow{2}{*}{$\pi-\pi^{*}$} & \multirow{2}{*}{$\mathrm{C}_{2}-\mathrm{C}_{9}$} & \multirow{2}{*}{1.84672} & $\mathrm{C}_{1}-\mathrm{O}_{8}$ & 0.27626 & 19.61 & 0.29 & 0.070 \\
\hline & & & $\mathrm{C}_{11}-\mathrm{C}_{13}$ & 0.36081 & 10.35 & 0.31 & 0.053 \\
\hline \multirow{2}{*}{$\pi-\pi^{*}$} & \multirow{2}{*}{$\mathrm{C}_{11}-\mathrm{H}_{13}$} & \multirow{2}{*}{1.59905} & $\mathrm{C}_{2}-\mathrm{C}_{9}$ & 0.20456 & 16.54 & 0.28 & 0.064 \\
\hline & & & $\mathrm{C}_{16}-\mathrm{C}_{18}$ & 0.37626 & 20.00 & 0.27 & 0.066 \\
\hline \multirow{2}{*}{$\pi-\pi^{*}$} & \multirow{2}{*}{$\mathrm{C}_{12}-\mathrm{C}_{14}$} & \multirow{2}{*}{1.64201} & $\mathrm{C}_{11}-\mathrm{C}_{13}$ & 0.36081 & 18.02 & 0.28 & 0.063 \\
\hline & & & $\mathrm{C}_{16}-\mathrm{C}_{18}$ & 0.37626 & 23.02 & 0.27 & 0.071 \\
\hline \multirow{2}{*}{$\pi-\pi^{*}$} & \multirow{2}{*}{$\mathrm{C}_{16}-\mathrm{C}_{18}$} & \multirow{2}{*}{1.62904} & $\mathrm{C}_{11}-\mathrm{C}_{13}$ & 0.36081 & 22.40 & 0.29 & 0.072 \\
\hline & & & $\mathrm{N}_{21}-\mathrm{O}_{22}$ & 0.61931 & 27.72 & 0.14 & 0.060 \\
\hline$\pi$-n & $\mathrm{N}_{21}-\mathrm{O}_{22}$ & 1.98618 & $\mathrm{O}_{23}$ & 0.00001 & 12.31 & 0.17 & 0.078 \\
\hline \multirow{2}{*}{$\mathbf{n}-\pi^{*}$} & \multirow{2}{*}{$\mathrm{S}_{3}$} & \multirow{2}{*}{1.99933} & $\mathrm{C}_{2}-\mathrm{C}_{9}$ & 0.20456 & 20.80 & 0.27 & 0.068 \\
\hline & & & $\mathrm{C}_{5}-\mathrm{O}_{6}$ & 0.30842 & 26.81 & 0.24 & 0.073 \\
\hline \multirow{2}{*}{$\mathbf{n}-\sigma^{*}$} & \multirow{2}{*}{$\mathrm{O}_{6}$} & \multirow{2}{*}{1.99977} & $\mathrm{~S}_{3}-\mathrm{C}_{5}$ & 0.12678 & 34.23 & 0.41 & 0.107 \\
\hline & & & $\mathrm{C}_{5}-\mathrm{N}_{7}$ & 0.08409 & 25.92 & 0.67 & 0.121 \\
\hline \multirow{2}{*}{$\mathbf{n}-\pi^{*}$} & \multirow{2}{*}{$\mathrm{N}_{7}$} & \multirow{2}{*}{1.64162} & $\mathrm{C}_{1}-\mathrm{O}_{8}$ & 0.27626 & 52.96 & 0.28 & 0.111 \\
\hline & & & $\mathrm{C}_{5}-\mathrm{O}_{6}$ & 0.30842 & 57.77 & 0.27 & 0.112 \\
\hline \multirow{2}{*}{$\mathbf{n}-\sigma^{*}$} & \multirow{2}{*}{$\mathrm{O}_{8}$} & \multirow{2}{*}{1.84905} & $\mathrm{C}_{1}-\mathrm{C}_{2}$ & 0.08163 & 21.71 & 0.65 & 0.108 \\
\hline & & & $\mathrm{C}_{1}-\mathrm{N}_{7}$ & 0.08215 & 28.44 & 0.67 & 0.125 \\
\hline$n-\sigma^{*}$ & \multirow{2}{*}{$\mathrm{O}_{22}$} & \multirow{2}{*}{1.89629} & $\mathrm{C}_{16}-\mathrm{N}_{21}$ & 0.10456 & 12.10 & 0.56 & 0.074 \\
\hline$n-\pi^{*}$ & & & $\mathrm{~N}_{21}-\mathrm{O}_{23}$ & 0.05582 & 19.48 & 0.71 & 0.106 \\
\hline$n-\sigma^{*}$ & \multirow{2}{*}{$\mathrm{O}_{23}$} & 1.89788 & $\mathrm{C}_{16}-\mathrm{N}_{21}$ & 0.10456 & 12.12 & 0.56 & 0.074 \\
\hline $\mathrm{n}-\pi^{*}$ & & 1.44471 & $\mathrm{~N}_{21}-\mathrm{O}_{22}$ & 0.61931 & 162.33 & 0.14 & 0.138 \\
\hline$\pi-\pi^{*}$ & $\mathrm{C}_{1}-\mathrm{O}_{8}$ & 1.98018 & $\mathrm{C}_{2}-\mathrm{C}_{9}$ & 0.20456 & 79.54 & 0.02 & 0.070 \\
\hline
\end{tabular}

${ }^{\mathrm{a}} \mathrm{ED} / \mathrm{e}$ represents the electron density of donor and acceptor of NBO orbitals.

${ }^{b} E^{(2)}$ is the energy of hyper-conjugative interactions (Stabilizing energy).

${ }^{c} E(j)-E(i)$ means the energy variance between donor and acceptor $i$ and $j$ NBO orbitals.

${ }^{d} F(i, j)$ is the Fock matrix element between $i$ and $j$ NBO orbitals.

\subsection{FMOs, global reactivity, and UV-Vis analysis.}

Frontier molecular orbitals (FMOs) (the highest occupied molecular orbital (HOMO) and lowest occupied molecular orbital (LUMO)) are extremely relevant for optical/electric properties of a given molecule, but also in quantum chemistry and UV-Vis spectra [51]. FMOs for 53NAT24D are illustrated in Figure 4.

HOMO denotes the outermost orbital filled by electrons, and it is correlated to the ionization potential and acts as an electron donor. The LUMO is the first empty innermost orbital unfilled by electron, and it is directly associated with the electron affinity and acts as an electron acceptor. The energy gap established considering HOMO and LUMO's energies specifies the molecular chemical stability and represents a crucial parameter employed for determining molecular electrical transport properties. Additionally, several features, including kinetic stability, chemical reactivity, chemical hardness and softness, polarizability, and electronegativity, are routinely assessed considering the energy gap between HOMO and LUMO [52,53]. In fact, compounds showing a large energy gap between HOMO and LUMO are known as "hard molecules", while chemical entities possessing small HOMO-LUMO 
energy gaps are considered "soft molecules". Accordingly, a compound with the smallest energy difference between HOMO and LUMO becomes more reactive.

\section{LUMO/ First excited state}

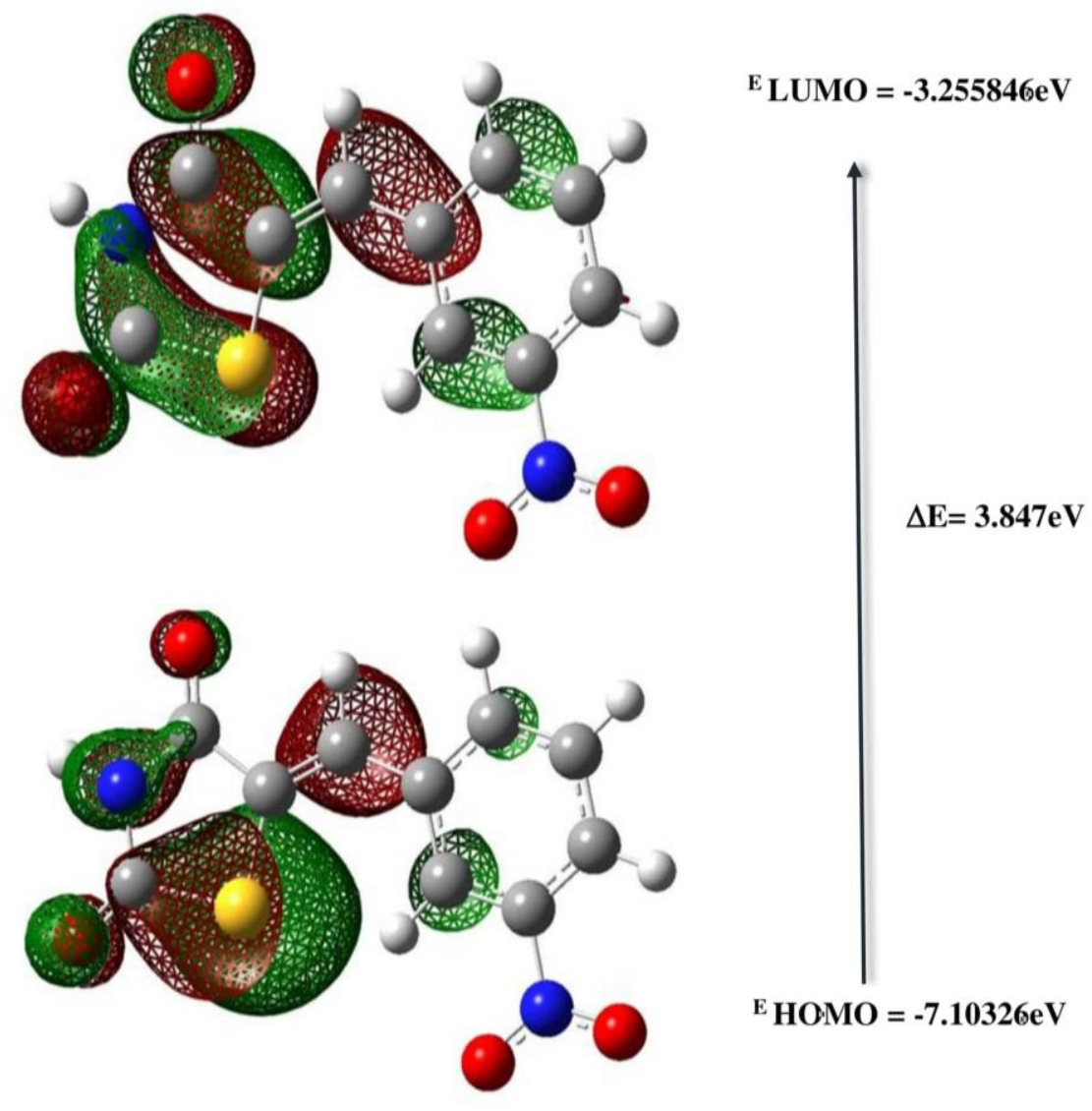

\section{HOMO/ Ground state}

Figure 4. HOMO-LUMO plot of 53NAT24D calculated at the B3LYP/6-31+G(d,p) level of theory.

In our study, 53NAT24D showed a small energy gap $(\Delta \mathrm{E})$ value between HOMO and LUMO, with an appropriate softness value, indicating that the molecule possesses a significant reactivity.

Moreover, using the equations reported in the Materials and Methods section, other reactivity factors were estimated for 53NAT24D (Table 5). Notably, these novel reactivity parameters help understand various pollutants' toxicity as recently described [54,55].

Table 5. Global reactivity descriptors values of 53NAT24D.

\begin{tabular}{l|l} 
Global reactivity descriptors & Values \\
\hline Ionisation potential(I) eV & 7.10326 \\
\hline Electron affinity(A) eV & 3.25584 \\
\hline Chemical hardness( $\boldsymbol{\eta})$ & 1.92371 \\
\hline Softness(S) & 0.51983 \\
\hline Chemical potential $(\boldsymbol{\mu})$ & -5.17955 \\
\hline Electronegativity $(\boldsymbol{\chi})$ & 5.17955 \\
\hline Electrophilicity index $(\dot{\boldsymbol{\omega}})$ & 13.41387
\end{tabular}

The symbol $\omega$ indicates possible bioactivity of 53NAT24D. The $\chi$ represents the ability of molecules to attract an electron. The experimental compound showed a significant electronegativity value. The $\eta$ and $S$ are important parameters for understanding the behavior of a chemical system. A higher value of hardness than softness value indicates relatively a hard 
molecule. The value of $\omega$, that provides insights about the stabilization energy when the considered system becomes saturated by electrons belonging to the external environment. These pieces of evidence about the reactivity indicate if a studied compound can donate a charge. For example, a reactive nucleophile is described by a lower value of $\omega$; on the contrary, higher $\omega$ values specify the existence of an important electrophile. The experimental data indicate that 53NAT24D has a $\omega$ value of 13.41387, which means that the compound is a good electrophile. The UV-Vis spectral analysis of 53NAT24D was completed as indicated in the Experimental section, and the output of this kind of calculation is reported in Table 6.

Table 6. Calculated electronic absorption spectral parameters of 53NAT24D.

\begin{tabular}{|c|c|c|c|c|c|}
\hline \multirow[b]{2}{*}{ SL } & \multirow{2}{*}{$\begin{array}{c}\text { Excitation } \\
\text { energies- } \\
(\mathrm{kcal} / \mathrm{mol})\end{array}$} & \multirow{2}{*}{$\begin{array}{c}\text { Wavelengths } \\
(\mathrm{nm})-\lambda_{\max }\end{array}$} & \multirow{2}{*}{$\begin{array}{l}\text { Oscillator } \\
\text { strength- } \\
\text { (f) } \\
\end{array}$} & \multicolumn{2}{|c|}{ Molecular contribution } \\
\hline & & & & $\begin{array}{c}\text { Major } \\
\text { contribution }\end{array}$ & $\begin{array}{c}\text { Minor } \\
\text { contribution }\end{array}$ \\
\hline 1 & 79.97 & 357.520 & 0.009 & $\mathrm{H}-1>\mathrm{L}(82 \%)$ & $\begin{array}{l}\text { H-6>L (4\%), } \\
\text { H-5->L (4\%) }\end{array}$ \\
\hline 2 & 83.03 & 344.334 & 0.222 & $\begin{array}{c}\mathrm{H}>\mathrm{L}(81 \%), \\
\mathrm{H}>\mathrm{L}+1 \\
(13 \%)\end{array}$ & $\mathrm{H}-1>\mathrm{L}(4 \%)$ \\
\hline 3 & 85.15 & 335.791 & 0.001 & $\begin{array}{c}\mathrm{H}-3>\mathrm{L}+1 \\
(85 \%)\end{array}$ & $\mathrm{H}-3>\mathrm{L}(9 \%)$ \\
\hline
\end{tabular}

The UV-Vis spectrum of 53NAT24D is reported in Figure 5, indicating that the absorption maxima $\lambda_{\max }$ for the low-lying singlet states of 53NAT24D displays the highest $\lambda_{\max }$ $=344.33$ and the oscillator strength (f) value of 0.222 . The maximum absorption wavelength of 53NAT24D corresponds to the electronic transition from HOMO > LUMO (81\%) and HOMO-1 > LUMO (13\%) for the main contribution and HOMO-1 > LUMO (4\%) for the minor contribution. The detected transition from HOMO $\rightarrow$ LUMO is $\pi \rightarrow \pi^{*}$.

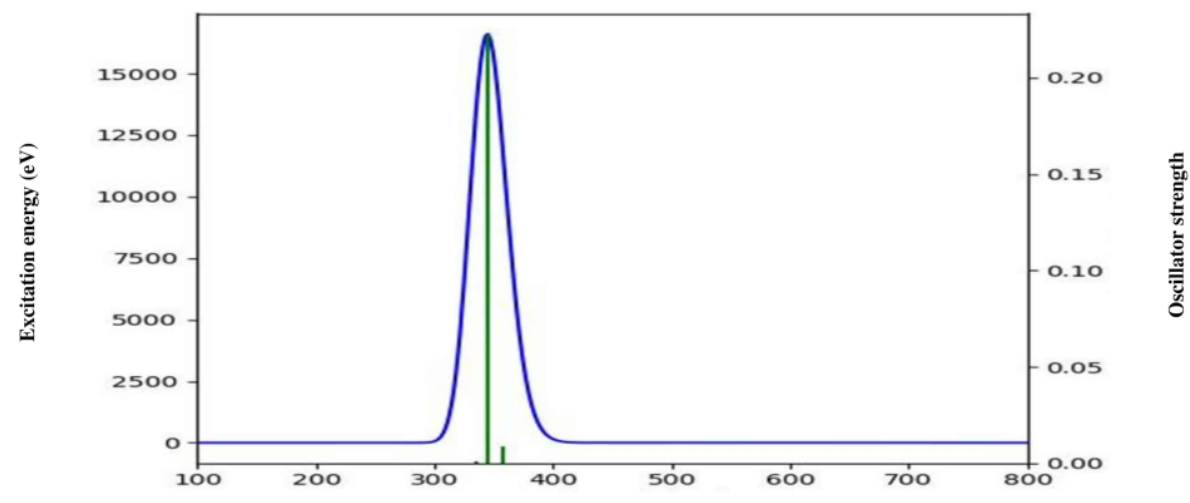

Figure 5. Calculated UV-Vis spectrum of 53NAT24D in the gas phase.

\subsection{Vibrational spectral analysis.}

The vibrational band assignments were done considering the normal coordinate analysis. Internal coordinates of 53NAT24D were built following Pulay's suggestions [56]. The estimated wavenumbers were selectively scaled, taking into account the scaled quantum mechanical (SQM) technique employing scale factors [57], with the root mean square (RMS) wavenumber error, which is in the realistic limit for an appropriate assignment. The vibrational assignments considering the SQM force field are reported in Table 7, while the calculated FTIR spectra are depicted in Figure 6. Notably, the estimated frequencies are in line with the obtainable experimental information. 
Table 7. Experimental and calculated IR frequencies $\left(\mathrm{cm}^{-1}\right)$ for 53NAT24D (atoms were previously reported).

\begin{tabular}{|c|c|c|}
\hline $\begin{array}{l}\text { Mode of } \\
\text { Vibration }\end{array}$ & Experimenta & $\begin{array}{l}\text { I Calculated Scaled Infra-Red } \\
\text { (IR) frequencies, } \mathbf{F}^{\mathrm{S}}\left(\mathrm{cm}^{-1}\right)\end{array}$ \\
\hline${ }_{v}\left(\mathrm{C}_{5}-\mathrm{N}_{7}\right)$ & & 1112 \\
\hline${ }_{\delta}(\mathrm{C}-\mathrm{H})_{\mathrm{Ar}}$ & & 1155 \\
\hline$\delta\left(\mathrm{C}_{9}-\mathrm{H}_{10}\right)_{\mathrm{Al}}$ & & 1308 \\
\hline$\delta\left(\mathrm{N}_{7}-\mathrm{H}_{4}\right)$ & & 1440 \\
\hline$v_{A s}\left(O_{22}=N_{21}=O_{23}\right)$ & & 1545 \\
\hline$v\left(C_{2}=C_{9}\right)$ & & 1599 \\
\hline${ }_{v}(C=C)_{A r}$ & $1566 \sim 1582$ & 1606 \\
\hline${ }_{v}\left(C_{1}=O_{8}\right)$ & & 1723 \\
\hline${ }_{v}\left(C_{5}=O_{6}\right)$ & $1667 \sim 1740$ & 1762 \\
\hline$v\left(\mathrm{C}_{9}-\mathrm{H}_{10}\right)_{\mathrm{Al}}$ & & 3054 \\
\hline${ }_{v}\left(C_{12}-H_{15}\right)_{A r}$ & & 3079 \\
\hline$v\left(\mathrm{C}_{14-\mathrm{H}_{19}}\right)_{\mathrm{Ar}}$ & & 3097 \\
\hline$v\left(C_{18}-H_{20}\right)_{A r}$ & & 3129 \\
\hline$v\left(C_{13}-H_{17}\right)_{A r}$ & & 3136 \\
\hline$v\left(\mathbf{N}_{7}-\mathbf{H}_{4}\right)$ & & 3485 \\
\hline
\end{tabular}

Calculated values were corrected by multiplying the frequency factor, $\mathrm{f}=0.964 ; \mathrm{v}=$ Stretching, $\mathrm{v}_{\mathrm{As}}=$ Asymmetric Stretching, $\delta=$ Bending, $\delta_{\mathrm{S}}=$ Scissoring, $\mathrm{F}^{\mathrm{S}}=$ Scaled frequency, $\mathrm{Ar}=$ Aromatic, $\mathrm{Al}=$ Aliphatic

\subsubsection{C-N vibrations.}

The detection of $\mathrm{C}=\mathrm{N}$ and $\mathrm{C}-\mathrm{N}$ vibrations represent a challenging task since a mix of vibrations are plausible in the considered region. Based on the observation reported by Silverstein and colleagues [58], the $\mathrm{C}-\mathrm{N}$ stretching absorption, regarding aromatic amines, ranging from 1382 to $1266 \mathrm{~cm}^{-1}$. Our FT-IR investigation shows that the $\mathrm{C}-\mathrm{N}$ stretching vibrations band was detected at $1112 \mathrm{~cm}^{-1}$ in the spectrum.

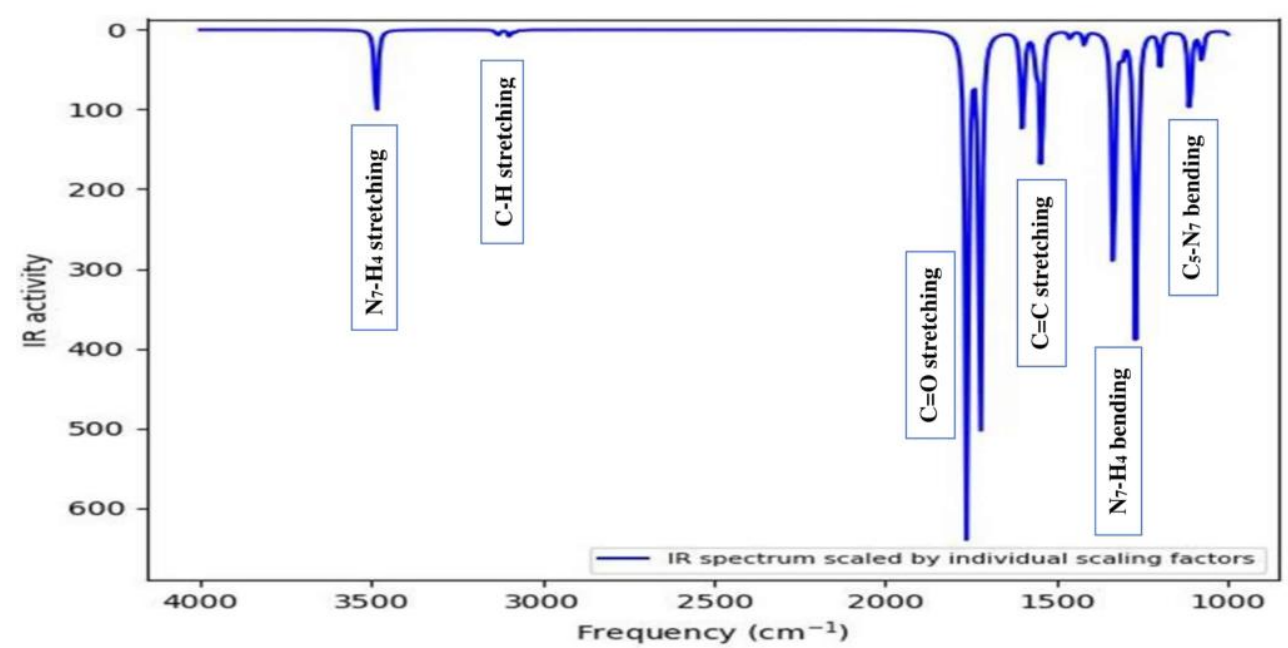

Figure 6. Fourier transform-infra red (FT-IR) spectrum of 53NAT24D in the wavenumber range 4000$1000 \mathrm{~cm}^{-1}$.

\subsubsection{C-H vibrations.}

Molecules containing aromatic portions usually show numerous weak bands in the 3100-3000 $\mathrm{cm}^{-1}$ region due to aromatic $\mathrm{C}-\mathrm{H}$ stretching vibrations [59]. The bands detected at $3079 \sim 3136 \mathrm{~cm}^{-1}$ in the FT-IR spectrum are ascribable to the $\mathrm{C}-\mathrm{H}$ ring stretching vibrations, and in-plane bending vibrations are commonly detected in the range of $1000-1300 \mathrm{~cm}^{-1}$. Based on the actual investigation, we found that the $\mathrm{C}-\mathrm{H}$ in-plane bending vibrations of 53NAT24D 
is detected at $1308 \mathrm{~cm}^{-1}$ and $1155 \mathrm{~cm}^{-1}$ in the aliphatic region and in the aromatic portion, respectively.

\subsubsection{N-H vibrations.}

Generally, regarding the primary aromatic amines, the $\mathrm{NH}$ stretching vibration is commonly found at $3500-3300 \mathrm{~cm}^{-1}$ of the IR spectra [60]. For 53NAT24D, we detected a robust symmetric stretching vibration of $\mathrm{NH}$ at $3485 \mathrm{~cm}^{-1}$. The $\mathrm{N}-\mathrm{H}$ in-plane bending vibrations are normally detected at $1630-1500 \mathrm{~cm}^{-1}$ and are characterized by robust IR bands [61]. Accordingly, our investigation revealed that the medium-strong band at $1440 \mathrm{~cm}^{-1}$ in FTIR is referred to as $\mathrm{N}-\mathrm{H}$ in-plane bending vibration.

\subsection{4. $\mathrm{NO}_{2}$ vibrations.}

The common set of frequencies produced by $\mathrm{NO}_{2}$ are typically dependent on the rest of the compound. The nitro group vibrations are normally related to symmetric and antisymmetric stretching, in-plane bending vibrations including scissoring and rocking, and outof-plane bending, which comprises wagging and twisting modes. Asymmetric stretching vibrations related to the $\mathrm{NO}_{2}$ function were found at $1570-1485 \mathrm{~cm}^{-1}$ [62], while symmetric vibrations at $1370-1320 \mathrm{~cm}^{-1}$. Rajamani and colleagues [63] detected the asymmetric stretching mode at $1570 \mathrm{~cm}^{-1}$ in 4-nitrophenoxyphenyl. The investigation of 53NAT24D provided one $\mathrm{NO}_{2}$ stretching vibration at $1545 \mathrm{~cm}^{-1}$ (asymmetric mode). The presence of $\mathrm{NO}_{2}$ bands specifies that the stretching frequencies are not influenced, whereas some mix of $\mathrm{CC}$ vibrations in bending frequencies.

\subsection{5. $\mathrm{C}=\mathrm{C}$ vibrations.}

The CC stretching vibrations for phenyl ring ranging from 1600 to $1400 \mathrm{~cm}^{-1}$ [64], where the bands between $1600-1500 \mathrm{~cm}^{-1}$ are linked to $\mathrm{C}=\mathrm{C}$ stretching and the rest to $\mathrm{C}-\mathrm{C}$ stretching, although no such distinction exists within the ring. In this study, the bands detected at 1599 and $1606 \mathrm{~cm}^{-1}$ are related to $\mathrm{C}=\mathrm{C}$, highlighted by experimental data at $1582 \mathrm{~cm}^{-1}$.

\subsubsection{Carbonyl $(\mathrm{C}=\mathrm{O})$ group vibrations.}

The $\mathrm{C}=\mathrm{O}$ stretching vibrations produce specific bands in IR spectra, and their intensity can be augmented due to the conjugation or formation of hydrogen bonds. The $\mathrm{C}=\mathrm{O}$ stretching of ketones is predictable at $1760-1730 \mathrm{~cm}^{-1}$ [65]. $\mathrm{C}=\mathrm{O}$ stretching mode is not an independent vibrational mode since it is coupled with vibrations of adjacent groups. The FT-IR bands with robust intensity at $1723 \mathrm{~cm}^{-1}$ (amine) and $1762 \mathrm{~cm}^{-1}$ (alone) are related to the carbonyl stretching mode of 53NAT24D.

\subsection{NMR analysis.}

As reported in the experimental part, after optimizing the molecular geometry of 53NAT24D, the ${ }^{1} \mathrm{H}$ and ${ }^{13} \mathrm{C}$ nuclear magnetic resonance (NMR) chemical shift data were estimated at the B3LYP/6-31+G(d,p) level using chloroform as a solvent and paralleled with experimental values obtained with $\mathrm{CDCl}_{3}$ as solvent using TMS as control [66]. The ${ }^{1} \mathrm{H}$ and ${ }^{13} \mathrm{C}$ NMR studies, including calculated and experimental data, are reported in Table 8, while the ${ }^{1} \mathrm{H}$ and ${ }^{13} \mathrm{C}$ NMR spectra and chemical shift values are detailed in Figures 7 and 8 , respectively. 
Table 8. Experimental and in silico ${ }^{1} \mathrm{H}$ NMR and ${ }^{13} \mathrm{C}$ NMR isotropic chemical shift (control: TMS and chloroform as solvent) of 53NAT24D.

\begin{tabular}{l|l|l|l|l|l} 
No & Expt. & $\begin{array}{l}\text { Chemical } \\
\text { shift-ppm }\end{array}$ & No & Expt. & $\begin{array}{l}\text { Chemical } \\
\text { shift-ppm }\end{array}$ \\
\hline $\mathbf{H}_{\mathbf{4}}$ & 8.48 & 7.681 & $\mathrm{C}_{1}$ & 169.86 & 152.4 \\
\hline $\mathbf{H}_{\mathbf{1 0}}$ & 7.57 & 8.254 & $\mathrm{C}_{2}$ & 119.55 & 118.0 \\
\hline $\mathbf{H}_{15}$ & 8.34 & 8.349 & $\mathrm{C}_{5}$ & 166.89 & 155.2 \\
\hline $\mathbf{H}_{\mathbf{1 7}}$ & 8.35 & 8.874 & $\mathrm{C}_{9}$ & 125.25 & 120.6 \\
\hline $\mathbf{H}_{19}$ & 8.09 & 8.112 & $\mathrm{C}_{11}$ & 128.42 & 121.9 \\
\hline $\mathbf{H}_{\mathbf{2 0}}$ & 8.09 & 8.929 & $\mathrm{C}_{12}$ & 125.93 & 129.2 \\
\hline & & & $\mathrm{C}_{13}$ & 112.58 & 111.3 \\
\hline & & & $\mathrm{C}_{14}$ & 114.32 & 116.9 \\
\hline & & & $\mathrm{C}_{16}$ & 134.74 & 136.3 \\
\hline & & & $\mathrm{C}_{18}$ & 120.14 & 113.4 \\
& & & \multicolumn{3}{c}{ нмR }
\end{tabular}

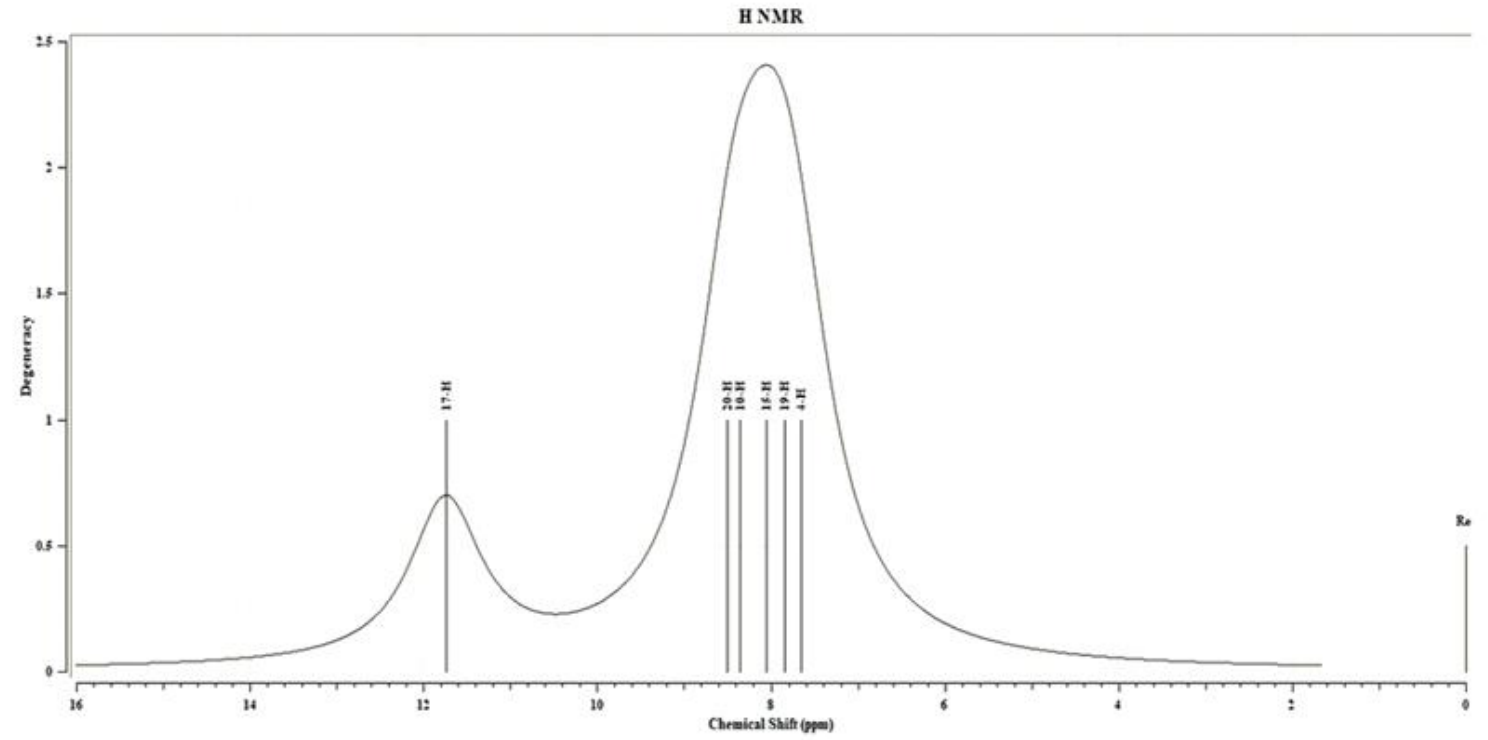

Figure 7. The ${ }^{1} \mathrm{H}$ NMR spectrum of 53NAT24D obtained employing chloroform as solvent.

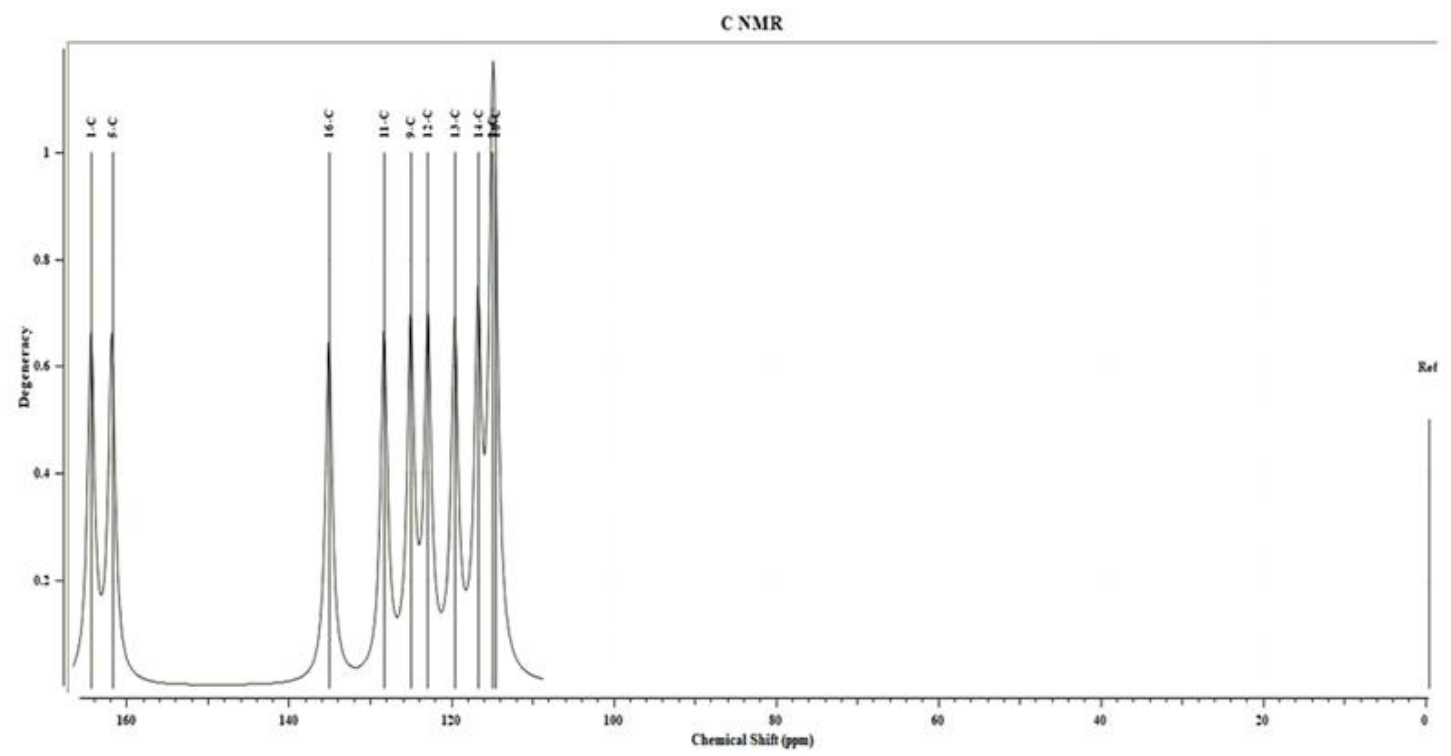

Figure 8. The ${ }^{13} \mathrm{C}$ NMR spectrum of 53NAT24D obtained employing chloroform as solvent.

The ${ }^{1} \mathrm{H}$ atoms chemical shift values of 53NAT24D ranging from 7.578 to $8.482 \mathrm{ppm}$. This data is ascribable to the hydrogen atoms belonging to the benzene and thiazolidine rings. The estimated chemical shifts of aromatic ${ }^{13} \mathrm{C}$ the ranging from 111.3 to $155.7 \mathrm{ppm}$. The highest ${ }^{13} \mathrm{C}$ chemical shift value of 53NAT24D is reported for the carbon atom linked to the https://biointerfaceresearch.com/ 
thiazolidine ring's oxygen atom. Because of the oxygen atom's electronegativity, its chemical shift values become greater with respect to the others. The maximum values found for 53NAT24D in chloroform solvent are 155.2, 152.4, and $136.3 \mathrm{ppm}$ regarding $\mathrm{C}_{5}, \mathrm{C}_{1}$, and $\mathrm{C}_{16}$ atom, respectively. The minimum chemical shift value ${ }^{13} \mathrm{C}$ of $53 \mathrm{NAT} 24 \mathrm{D}$ is related to the $\mathrm{C}_{13}$ atom belonging to the benzene moiety; this value is smaller than the other carbons (113.4 ppm for the $\mathrm{C}_{18}$ atom, $116.9 \mathrm{ppm}$ for the $\mathrm{C}_{14}, 120.6 \mathrm{ppm}$ for the $\mathrm{C}_{9}$, and $121.9 \mathrm{ppm}$ for the $\mathrm{C}_{11}$ atom). As reported in Table 8, the calculated ${ }^{13} \mathrm{C}$ NMR chemical shift values for 53NAT24D are consistent with the experimental observations [67].

\section{(A)}
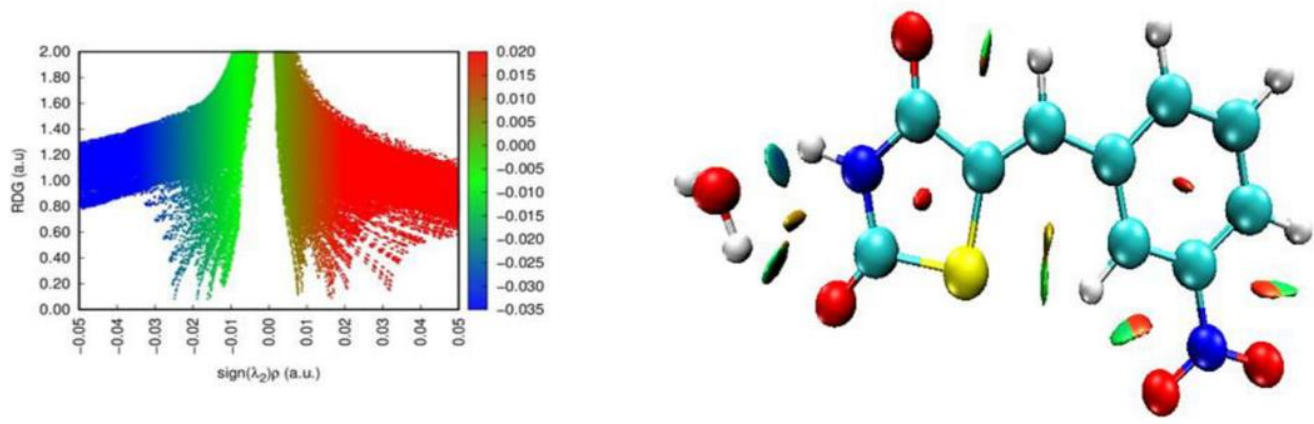

(B)
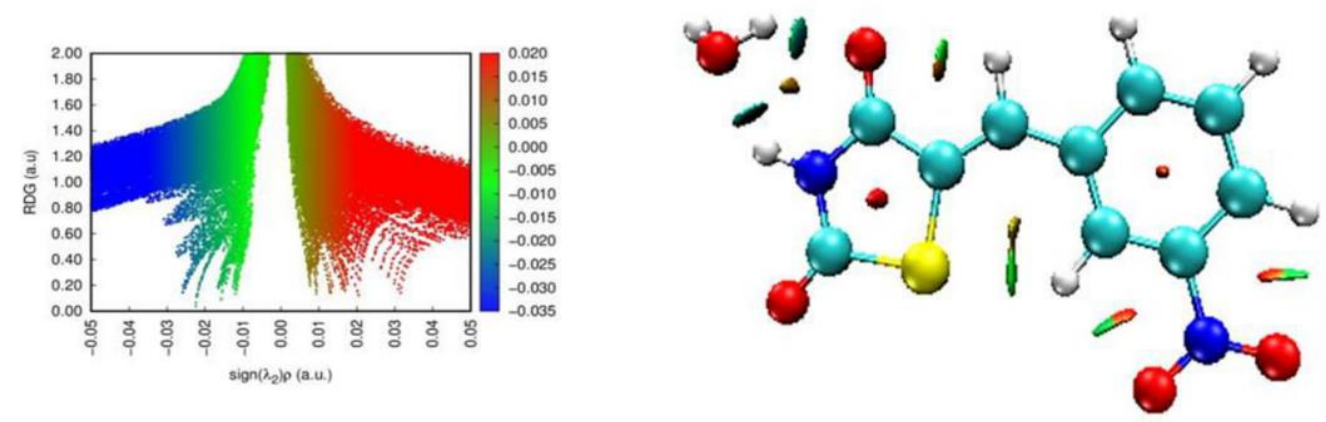

(C)
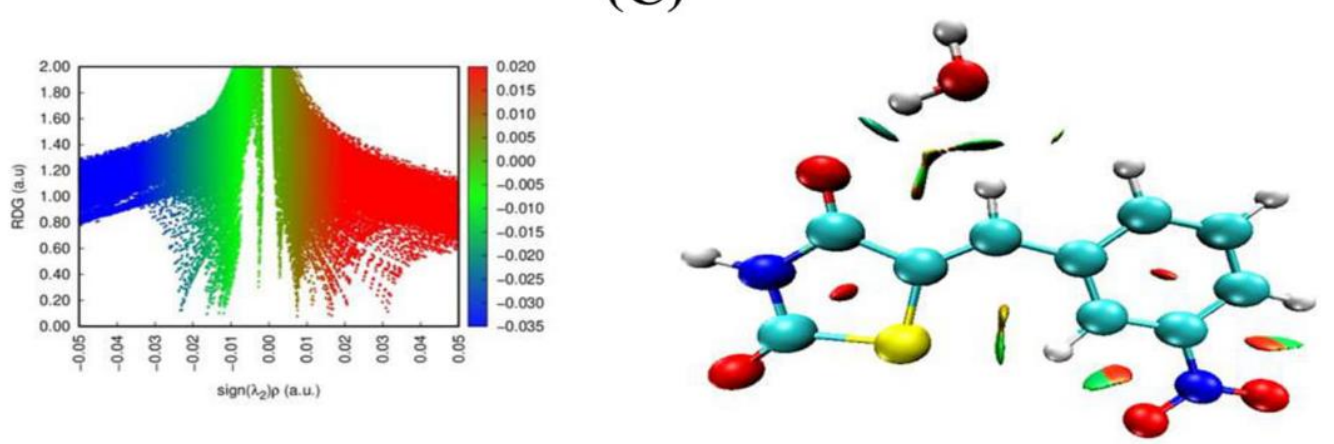

Figure 9. The sign $\left(\lambda_{2}\right) \rho$ vs RDG (left) and the gradient isosurfaces (right) for 53NAT24D with water $\left(\mathrm{O}_{6} \ldots . . . \mathrm{H}\right.$ \& $\left.\mathrm{H}_{4} \ldots \ldots . \mathrm{O}\right) \mathrm{B} .\left(\mathrm{H}_{4} \ldots \ldots \mathrm{O} \& \mathrm{O}_{8} \ldots . \mathrm{H}\right) \mathrm{C} .\left(\mathrm{O}_{8} \ldots \ldots . \mathrm{H} \& \mathrm{H}_{10} \ldots . . \mathrm{O}\right)$ positions, blue indicate sign $\left(\lambda_{2}\right) \rho<0$ (hydrogen region), green indicate sign $\left(\lambda_{2}\right) \rho=0$ (van der Waals region), red indicate sign $\left(\lambda_{2}\right) \rho>0$ (steric region).

\subsection{Non-covalent interactions analysis.}

For visualizing NCI in real space, an efficient strategy described by Yang and coworkers can also be used to investigate hydrogen bond properties. Accordingly, NCI analyses are an appropriate method to acquire info regarding intramolecular and intermolecular 
interactions, distinguishing types and strength of interactions [24]. Diverse kind of interactions and related intensities are investigated by electron density $(\rho(\mathrm{r}))$ and their RDG isosurfaces analysis. In this work, the eigenvalue $\lambda_{2}>0$ and $\lambda_{2}<0$ mean bonding and antibonding interactions, respectively. When $\left(\lambda_{2}(r)\right) \rho(r)$ is a large and negative value indicating attractive interactions such as H-bonds, while when is large and positive could be indicative of antibonding interactions such as steric repulsions, also, when $\left(\lambda_{2}(r)\right) \rho(r)$ is close to zero, it is indicative of the van der Waals interactions. Figure 9 reports the plots of RDG versus $\left(\lambda_{2}\right) \rho$, and the gradient isosurface ( $\mathrm{s}=0.5$ a.u..) for 53NAT24D with water in $\left(\mathrm{O}_{6} \ldots \ldots . . . \mathrm{H}\right.$ and $\mathrm{H}_{4} \ldots . . \mathrm{O}$, $\mathrm{H}_{4} \ldots \ldots \mathrm{O}$ and $\mathrm{O}_{8} \ldots . \mathrm{H}, \mathrm{O}_{8} \ldots \ldots . \mathrm{H}$ and $\left.\mathrm{H}_{10} \ldots . . \mathrm{O}\right)$ positions respectively, for investigating interaction types and strength. In particular, in the figure (left side), the peaks at the sign $\left(\lambda_{2}\right) \rho$ $<0$ region suggested attractive contacts like hydrogen bond and $\pi-\pi$ stacking, whereas the spikes close to signing $\left(\lambda_{2}\right) \rho=0$ exhibit van der Waals contacts. Contrarily, peaks at the sign $\left(\lambda_{2}\right) \rho>0$ region specify steric effects. Regarding the gradient isosurface pictorial representation, the interactions and their strength can be recognized through analyzing the color and area. As reported in the figure for the title compound with water in $\left(\mathrm{O}_{6} \ldots \ldots . . . \mathrm{H}\right.$ and $\mathrm{H}_{4} \ldots . . . \mathrm{O}$, $\mathrm{H}_{4} \ldots . . \mathrm{O}$ and $\mathrm{O}_{8} \ldots . \mathrm{H}, \mathrm{O}_{8} \ldots \ldots . . . \mathrm{H}$ and $\left.\mathrm{H}_{10} \ldots . . \mathrm{O}\right)$ positions respectively, the compound shows no peak in the strong hydrogen bond region (-0.04 - 0.03 a.u.). On the contrary, 53NAT24D shows the spikes at $(-0.03 \sim-0.02$ a.u.) the region, suggesting a weaker hydrogen bond. Moreover, van Der Waals and steric effect regions are also shown in Figure 9.

\subsection{ADME and PASS prediction analysis.}

Additional computational studies were performed to add further information about the selected molecule. In particular, we evaluated the drug-like profile and possible biological activities.

Table 9. Physicochemical profile of 53NAT24D.

\begin{tabular}{c|c|c|c|c|c|c|c} 
Compound & MW & HBA & HBD & $\log$ P & AMR & TPSA & $\begin{array}{c}\text { Lipinski's } \\
\text { Violations }\end{array}$ \\
\hline Rule & $<\mathbf{5 0 0}$ & $\leq \mathbf{1 0}$ & $\leq \mathbf{5}$ & $\leq \mathbf{5}$ & $\begin{array}{c}\mathbf{4 0 -} \\
\mathbf{1 3 0}\end{array}$ & $\leq \mathbf{1 4 0}\left(\AA^{2)}\right.$ & $\leq \mathbf{1}$ \\
\hline 53NAT24D & 250.23 & 4 & 1 & 1.12 & 67.95 & 117.29 & 0
\end{tabular}

For this reason, the predicted molecular properties were broken down into certain parameters, for example, molecular weight $(<500 \mathrm{~g} / \mathrm{mol})$, hydrogen bond acceptor $(\leq 10)$, hydrogen bond giver $(\leq 5), \log \mathrm{P}(<5)$, molar refractivity $(40-130)$ and topological polar surface area (TPSA) (Table 9). The output indicated that 53NAT24D possesses a significant drug-like profile. Moreover, no violation of Lipinski's rule of five was found. Accordingly, due to the good ADME properties, 53NAT24D could represent an excellent pharmacological tool.

In addition, 53NAT24D was computationally investigated about its possible biological potential. PASS online web-server was used for this purpose, and the results of this investigation are illustrated in Table 10. PASS is an online instrument utilized for assessing the possible biological potential of a given compound. The output of this calculation indicates that 53NAT24D showed more plausible action $(\mathrm{Pa})$ respect than $\mathrm{Pi}$ (likely inertia). This calculation suggested that 53NAT24D could have anti-inflammatory, anticonvulsant, antitumor, antimicrobial, and anti-viral activity. Accordingly, this calculation's output provides a series of potential biological activities possessing suitable $\mathrm{Pa}$ and $\mathrm{Pi}$ ratio. $\mathrm{Pa}$ and $\mathrm{Pi}$ estimate the 
probability of a molecule to show activity or not. Overall, the present experiment suggested a potential pharmacological activity of 53NAT24D.

Table 10. Biological activities predicted for 53NAT24D using PASS online web-server.

\begin{tabular}{c|c|c|c} 
Compounds & Biological activity & Pa & Pi \\
\hline \multirow{4}{*}{ 53NAT24D } & Anti-microbial & 0.177 & 0.140 \\
\cline { 2 - 4 } & Anti-inflammatory & 0.312 & 0.009 \\
\cline { 2 - 4 } & Anti-tumor & 0.388 & 0.019 \\
\cline { 2 - 4 } & Anti-viral & 0.287 & 0.100 \\
\cline { 2 - 4 } & Anti-convulsant & 0.177 & 0.140
\end{tabular}

\subsection{Molecular docking study.}

Receptor-based molecular docking was accomplished using 53NAT24D with several potential drug targets involved in a plethora of biological effects showed by thiazolidine-2,4dione core and highlighted by PASS output (further details can be found in Materials and Methods).

Table 11. Docking result of 53NAT24D, Acetazolamide, Oseltamivir, Diclofenac Sodium, Doxorubicin, Amoxicillin with different enzymes for an anticonvulsant, anti-viral, anti-microbial, anti-inflammatory, and antitumor profile.

\begin{tabular}{l|l|lll|l|l}
$\begin{array}{l}\text { Molecule } \\
\text { Protein }\end{array}$ & 53NAT24D & Acetazolamide & Oseltamivir & $\begin{array}{l}\text { Diclofenac } \\
\text { Sodium }\end{array}$ & Doxorubicin & Amoxicillin \\
\hline 2A1H & -5.6 & -4.6 & - & - & - & - \\
\hline 3OYS & -4.4 & -6.7 & - & - & - & - \\
\hline 2I6B & -7.2 & -5.5 & - & - & - & - \\
\hline 5RGX & -5.2 & - & -6.1 & - & - & - \\
\hline 4OW0 & -5.5 & - & -6.6 & - & - & - \\
\hline 4KHR & -6.0 & - & -6.9 & - & - & - \\
\hline 5U1R & -7.1 & - & - & -8.4 & - & - \\
\hline 1S1P & -6.7 & - & - & -5.9 & - & - \\
\hline 1S1R & -6.3 & - & - & -6.0 & - & - \\
\hline 1M17 & -7.4 & - & - & - & -6.4 & - \\
\hline 4UMX & -5.6 & - & - & - & -4.8 & - \\
\hline 3EXE & -6.3 & - & - & - & -6.0 & - \\
\hline 1HNJ & -6.2 & - & - & - & - & -5.2 \\
\hline 1W7K & -7.4 & - & - & - & - & -7.1 \\
\hline 1ZB6 & -8.1 & - & - & - & - & -6.0
\end{tabular}

The purpose of the molecular docking investigation was to investigate if 53NAT24D, as suggested by PASS, could act as an anticonvulsant, anti-viral, anti-microbial, antiinflammatory, and antitumor agent by modulating related drug targets in comparison with standard drugs. Accordingly, we selected several drug targets related to the potential activities highlighted by PASS. The potential binding affinities (docking score, $\mathrm{kcal} / \mathrm{mol}$ ) of 53NAT24D against the selected drug targets were reported in Table 11.

The present data showed that 53NAT24D has the highest binding affinity against Human Adenosine Kinase, HCV NS5B RNA-dependent RNA polymerase, human MR1, EGFR tyrosine kinase domain, ORF2 aromatic prenyltransferase (PDB ID: 2I6B, 4KHR, 5U1R, 1M17, 1ZB6, respectively) with docking scores of -7.237, -7.300, -7.126, -7.448, -8.275 $\mathrm{kcal} / \mathrm{mol}$, respectively; while standard drugs Acetazolamide, Oseltamivir, Diclofenac Sodium, Doxorubicin, and Amoxicillin showed -5.541, -5.900, -8.403, -6.402, -6.064 kcal/mol respectively. The retrieved binding modes of 53NAT24D within the mentioned targets are displayed in Figure 10. 
(A)

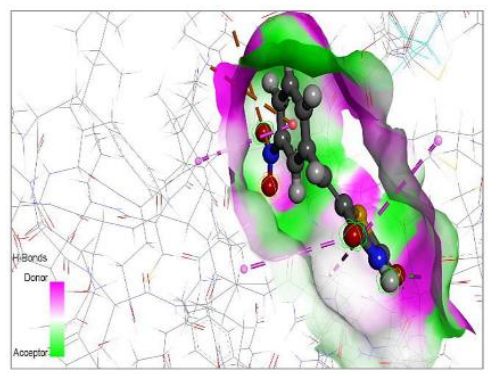

(B)

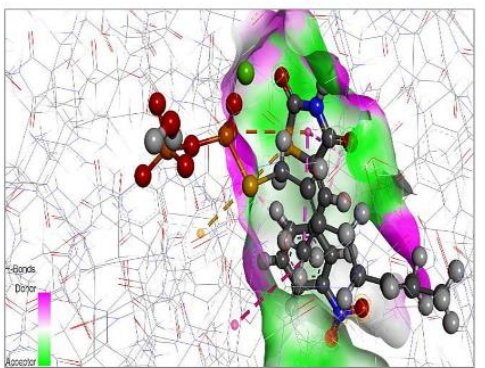

(C)

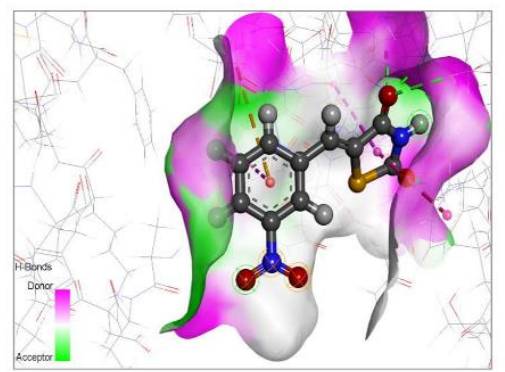

Figure 10. 3D view of 53NAT24D in complex with the active site of EGFR tyrosine kinase domain, ORF2, and human adenosine kinase proteins.

Among the possible targets, 53NAT24D showed promising pharmacological potential against EGFR $(-7.448 \mathrm{kcal} / \mathrm{mol})$ and ORF2 $(-8.275 \mathrm{kcal} / \mathrm{mol})$. According to these further computational studies, it might be conceivable that 53NAT24D may go about as a promising antitumor and anti-microbial agent.

\section{Conclusions}

In summary, we have presented the development of a computational procedure for characterizing, employing extensive ab initio calculations, the compound 53NAT24D. The MESP profile of 53NAT24D revealed that the positive region of the selected molecule could be subjected to a nucleophile attack. NBO analysis was performed, and the results suggested the possibility of the intramolecular charge transfer between the bonding and antibonding orbitals. HOMO-LUMO energies' findings were useful to investigate the charge transfer within the compound, which is accountable for potential bioactivity. Global reactivity descriptor values indicated the biological importance of 53NAT24D. Furthermore, the electronic properties were studied in-depth and were used to perform a comprehensive comparison concerning calculated and experimental data, suggesting the robustness of the employed methodology. In addition, molecular docking combined with ADME and PASS calculations was performed to better characterized 53NAT24D about its potential pharmacological targets. According to the present investigation, 53NAT24D had the likelihood of behaving as an inhibitor of EGFR and ORF2. Accordingly, although further studies are needed for exploiting the pharmacological potential of 53NAT24D, our computer-driven investigation suggests that this compound could represent a valuable starting point for developing molecules with promising antitumor and anti-microbial profiles.

\section{Funding}

This research received no external funding.

\section{Acknowledgments}

The authors are grateful to the Department of Theoretical and Computational Chemistry, University of Dhaka, Dhaka-1000, Bangladesh, for providing support and research facilities to accomplish this study.

\section{Conflicts of Interest}

The authors declare no conflict of interest. 


\section{References}

1. Cecil, R. Intramolecular bonds in proteins. I. The role of sulfur in proteins. The proteins, composition, structure, and function, Academic Press New York: 1963; Vol. 1, 379-476.

2. de Paiva, R.K.C.; Silva, J.F.d.; Moreira, H.A.; Pinto, O.G.; Camargo, L.T.F.M.; Naves, P.L.F.; Camargo, A.J.; Ribeiro, L.; Ramos, L.M. Synthesis, Antimicrobial Activity and Structure-Activity Relationship of Some 5-Arylidene-thiazolidine-2, 4-dione Derivatives. J. Braz. Chem. Soc. 2019, 30, 164-172.

3. da Silva, I.M.; da Silva Filho, J.; Santiago, P.B.G.d.S.; do Egito, M.S.; de Souza, C.A.; Gouveia, F.L.; Ximenes, R.M.; de Sena, K.X.d.F.R.; de Faria, A.R.; Brondani, D.J.; de Albuquerque, J.F.C. Synthesis and Antimicrobial Activities of 5-Arylidene-thiazolidine-2,4-dione Derivatives. BioMed Research International 2014, 2014, 316082, https://doi.org/10.1155/2014/316082.

4. Jain, V.S.; Vora, D.K.; Ramaa, C.S. Thiazolidine-2,4-diones: progress towards multifarious applications. Bioorg. Med. Chem. 2013, 21, 1599-1620, https://doi.org/10.1016/j.bmc.2013.01.029.

5. Donnelly, B.; Downie, T.C.; Grzeskowiak, R.; Hamburg, H.R.; Short, D. A study of the inhibiting properties of some derivatives of thiourea. Corros. Sci. 1974, 14, 597-606, https://doi.org/10.1016/S0010938X(74)80024-7.

6. Allen, S.; Newhouse, B.; Anderson, A.S.; Fauber, B.; Allen, A.; Chantry, D.; Eberhardt, C.; Odingo, J.; Burgess, L.E. Discovery and SAR of trisubstituted thiazolidinones as CCR4 antagonists. Bioorg. Med. Chem. Lett. 2004, 14, 1619-1624, https://doi.org/10.1016/j.bmcl.2004.01.072.

7. Sirous, H.; Chemi, G.; Gemma, S.; Butini, S.; Debyser, Z.; Christ, F.; Saghaie, L.; Brogi, S.; Fassihi, A.; Campiani, G.; Brindisi, M. Identification of Novel 3-Hydroxy-pyran-4-One Derivatives as Potent HIV-1 Integrase Inhibitors Using in silico Structure-Based Combinatorial Library Design Approach. Frontiers in Chemistry 2019, 7, 574, https://doi.org/10.3389/fchem.2019.00574.

8. Guedes, I.A.; de Magalhães, C.S.; Dardenne, L.E. Receptor-ligand molecular docking. Biophys. Rev. 2014, 6, 75-87, https://doi.org/10.1007/s12551-013-0130-2.

9. Chemi, G.; Gemma, S.; Campiani, G.; Brogi, S.; Butini, S.; Brindisi, M. Computational Tool for Fast in silico Evaluation of hERG K+ Channel Affinity. Frontiers in Chemistry 2017, 5, 7, https://doi.org/10.3389/fchem.2017.00007.

10. Citi, V.; Corvino, A.; Fiorino, F.; Frecentese, F.; Magli, E.; Perissutti, E.; Santagada, V.; Brogi, S.; Flori, L.; Gorica, E.; Testai, L.; Martelli, A.; Calderone, V.; Caliendo, G.; Severino, B. Structure-activity relationships study of isothiocyanates for $\mathrm{H} 2 \mathrm{~S}$ releasing properties: 3-Pyridyl-isothiocyanate as a new promising cardioprotective agent. Journal of Advanced Research 2021, 27, 41-53, https://doi.org/10.1016/j.jare.2020.02.017.

11. Zaccagnini, L.; Brogi, S.; Brindisi, M.; Gemma, S.; Chemi, G.; Legname, G.; Campiani, G.; Butini, S. Identification of novel fluorescent probes preventing PrPSc replication in prion diseases. Eur. J. Med. Chem. 2017, 127, 859-873, https://doi.org/10.1016/j.ejmech.2016.10.064.

12. Sirous, H.; Chemi, G.; Campiani, G.; Brogi, S. An integrated in silico screening strategy for identifying promising disruptors of p53-MDM2 interaction. Comput. Biol. Chem. 2019, 83, 107105, https://doi.org/10.1016/j.compbiolchem.2019.107105.

13. Dennington, R.D.; Keith, T.A.; Millam, J.M. GaussView 6.0. 16, Semichem. Inc., Shawnee Mission KS 2016.

14. Frisch, M.J.; Trucks, G.W.; Schlegel, H.B.; Scuseria, G.E.; Robb, M.A.; Cheeseman, J.R.; Scalmani, G.; Barone, V.; Petersson, G.A.; Nakatsuji, H. Gaussian 16 revision a. 03. 2016; gaussian inc. Wallingford CT 2016, 2.

15. Chibani, S.; Jacquemin, D.; Laurent, A.D. Modelling solvent effects on the absorption and emission spectra of constrained cyanines with both implicit and explicit QM/EFP models. Computational and Theoretical Chemistry 2014, 1040-1041, 321-327, https://doi.org/10.1016/j.comptc.2014.03.033.

16. Johnson, R.D.; Irikura, K.K.; Kacker, R.N.; Kessel, R. Scaling Factors and Uncertainties for ab Initio Anharmonic Vibrational Frequencies. J. Chem. Theory Comput. 2010, 6, 2822-2828, https://doi.org/10.1021/ct100244d.

17. Lu, T.; Chen, F. Multiwfn: A multifunctional wavefunction analyzer. J. Comput. Chem. 2012, 33, 580-592, https://doi.org/10.1002/jcc.22885.

18. Phillips, J.C. Generalized Koopmans' Theorem. Phys. Rev. 1961, 123, 420, https://doi.org/10.1103/PhysRev.123.420. 
19. Flippin, L.A.; Gallagher, D.W.; Jalali-Araghi, K. A convenient method for the reduction of ozonides to alcohols with borane-dimethyl sulfide complex. The Journal of Organic Chemistry 1989, 54, 1430-1432, https://doi.org/10.1021/jo00267a035.

20. Parr, R.G.; Szentpály, L.v.; Liu, S. Electrophilicity Index. J. Am. Chem. Soc. 1999, 121, 1922-1924, https://doi.org/10.1021/ja983494x.

21. Chattaraj, P.K.; Giri, S. Stability, Reactivity, and Aromaticity of Compounds of a Multivalent Superatom. The Journal of Physical Chemistry A 2007, 111, 11116-11121, https://doi.org/10.1021/jp0760758.

22. Padmanabhan, J.; Parthasarathi, R.; Subramanian, V.; Chattaraj, P.K. Electrophilicity-Based Charge Transfer Descriptor. The Journal of Physical Chemistry A 2007, 111, 1358-1361, https://doi.org/10.1021/jp0649549.

23. Ayers, P.W.; Parr, R.G. Variational Principles for Describing Chemical Reactions: The Fukui Function and Chemical Hardness Revisited. J. Am. Chem. Soc. 2000, 122, 2010-2018, https://doi.org/10.1021/ja9924039.

24. Contreras-García, J.; Johnson, E.R.; Keinan, S.; Chaudret, R.; Piquemal, J.-P.; Beratan, D.N.; Yang, W. NCIPLOT: A Program for Plotting Noncovalent Interaction Regions. J. Chem. Theory Comput. 2011, 7, 625632, https://doi.org/10.1021/ct100641a.

25. Tang, W.; Sanville, E.; Henkelman, G. A grid-based Bader analysis algorithm without lattice bias. J. Phys.: Condens. Matter 2009, 21, 084204, https://doi.org/10.1088/0953-8984/21/8/084204.

26. Lipinski, C.A.; Lombardo, F.; Dominy, B.W.; Feeney, P.J. Experimental and computational approaches to estimate solubility and permeability in drug discovery and development settings. Adv. Drug Del. Rev. 1997, 23, 3-25, https://doi.org/10.1016/s0169-409x(96)00423-1.

27. Natarajan, A.; Sugumar, S.; Bitragunta, S.; Balasubramanyan, N. Molecular docking studies of (4 Z , 12 Z )cyclopentadeca-4, 12-dienone from Grewia hirsuta with some targets related to type 2 diabetes. BMC Complement. Altern. Med. 2015, 15, 73, https://doi.org/10.1186/s12906-015-0588-5.

28. Pass online. Available online: http://www.pharmaexpert.ru/passonline/.

29. Sonmez, F.; Sevmezler, S.; Atahan, A.; Ceylan, M.; Demir, D.; Gencer, N.; Arslan, O.; Kucukislamoglu, M. Evaluation of new chalcone derivatives as polyphenol oxidase inhibitors. Bioorg. Med. Chem. Lett. 2011, 21, 7479-7482, https://doi.org/10.1016/j.bmcl.2011.09.130.

30. Worldwide Protein Data Bank. Available online: http://www.pdb.org.

31. Di Capua, A.; Sticozzi, C.; Brogi, S.; Brindisi, M.; Cappelli, A.; Sautebin, L.; Rossi, A.; Pace, S.; Ghelardini, C.; Di Cesare Mannelli, L.; Valacchi, G.; Giorgi, G.; Giordani, A.; Poce, G.; Biava, M.; Anzini, M. Synthesis and biological evaluation of fluorinated 1,5-diarylpyrrole-3-alkoxyethyl ether derivatives as selective COX2 inhibitors endowed with anti-inflammatory activity. Eur. J. Med. Chem. 2016, 109, 99-106, https://doi.org/10.1016/j.ejmech.2015.12.044.

32. Maquiaveli, C.C.; Lucon-Júnior, J.F.; Brogi, S.; Campiani, G.; Gemma, S.; Vieira, P.C.; Silva, E.R. Verbascoside Inhibits Promastigote Growth and Arginase Activity of Leishmania amazonensis. J. Nat. Prod. 2016, 79, 1459-1463, https://doi.org/10.1021/acs.jnatprod.5b00875.

33. Brogi, S.; Fiorillo, A.; Chemi, G.; Butini, S.; Lalle, M.; Ilari, A.; Gemma, S.; Campiani, G. Structural characterization of Giardia duodenalis thioredoxin reductase (gTrxR) and computational analysis of its interaction with NBDHEX. Eur. J. Med. Chem. 2017, 135, 479-490, https://doi.org/10.1016/j.ejmech.2017.04.057.

34. Battah, B.; Chemi, G.; Butini, S.; Campiani, G.; Brogi, S.; Delogu, G.; Gemma, S. A Repurposing Approach for Uncovering the Anti-Tubercular Activity of FDA-Approved Drugs with Potential Multi-Targeting Profiles. Molecules 2019, 24, https://doi.org/10.3390/molecules24234373.

35. Brindisi, M.; Ulivieri, C.; Alfano, G.; Gemma, S.; de Asís Balaguer, F.; Khan, T.; Grillo, A.; Chemi, G.; Menchon, G.; Prota, A.E.; Olieric, N.; Lucena-Agell, D.; Barasoain, I.; Diaz, J.F.; Nebbioso, A.; Conte, M.; Lopresti, L.; Magnano, S.; Amet, R.; Kinsella, P.; Zisterer, D.M.; Ibrahim, O.; O'Sullivan, J.; Morbidelli, L.; Spaccapelo, R.; Baldari, C.; Butini, S.; Novellino, E.; Campiani, G.; Altucci, L.; Steinmetz, M.O.; Brogi, S. Structure-activity relationships, biological evaluation and structural studies of novel pyrrolonaphthoxazepines as antitumor agents. Eur. J. Med. Chem. 2019, 162, 290-320, https://doi.org/10.1016/j.ejmech.2018.11.004.

36. da Silva, E.R.; Brogi, S.; Grillo, A.; Campiani, G.; Gemma, S.; Vieira, P.C.; Maquiaveli, C.d.C. Cinnamic acids derived compounds with antileishmanial activity target Leishmania amazonensis arginase. Chem. Biol. Drug Des. 2019, 93, 139-146, https://doi.org/10.1111/cbdd.13391.

37. da Silva, E.R.; Brogi, S.; Lucon-Júnior, J.F.; Campiani, G.; Gemma, S.; Maquiaveli, C.d.C. Dietary polyphenols rutin, taxifolin and quercetin related compounds target Leishmania amazonensis arginase. Food Funct. 2019, 10, 3172-3180, https://doi.org/10.1039/c9fo00265k. 
38. Reale, A.; Brogi, S.; Chelini, A.; Paolino, M.; Di Capua, A.; Giuliani, G.; Cappelli, A.; Giorgi, G.; Chemi, G.; Grillo, A.; Valoti, M.; Sautebin, L.; Rossi, A.; Pace, S.; La Motta, C.; Di Cesare Mannelli, L.; Lucarini, E.; Ghelardini, C.; Anzini, M. Synthesis, biological evaluation and molecular modeling of novel selective COX-2 inhibitors: sulfide, sulfoxide, and sulfone derivatives of 1,5-diarylpyrrol-3-substituted scaffold. Biorg. Med. Chem. 2019, 27, 115045, https://doi.org/10.1016/j.bmc.2019.115045.

39. Aziz, M.A.; Mehedi, M.; Akter, M.I.; Sajon, S.R.; Mazumder, K.; Rana, M.S. In vivo and in silico evaluation of analgesic activity of Lippia alba. Clinical Phytoscience 2019, 5, 38, https://doi.org/10.1186/s40816-0190133-z.

40. Brogi, S.; Sirous, H.; Calderone, V.; Chemi, G. Amyloid $\beta$ fibril disruption by oleuropein aglycone: longtime molecular dynamics simulation to gain insight into the mechanism of action of this polyphenol from extra virgin olive oil. Food Funct. 2020, 11, 8122-8132, https://doi.org/10.1039/d0fo01511c.

41. da Silva, E.R.; Come, J.A.; Brogi, S.; Calderone, V.; Chemi, G.; Campiani, G.; Oliveira, T.M.; Pham, T.-N.; Pudlo, M.; Girard, C.; Maquiaveli, C.D. Cinnamides Target Leishmania amazonensis Arginase Selectively. Molecules 2020, 25, https://doi.org/10.3390/molecules25225271.

42. Di Capua, A.; Reale, A.; Paolino, M.; Chemi, G.; Brogi, S.; Cappelli, A.; Giorgi, G.; Grande, F.; Di Cesare Mannelli, L.; Ghelardini, C.; Matucci, R.; Garofalo, A.; Anzini, M. Design, synthesis and biological evaluation of 7-substituted 4-phenyl-6H-imidazo[1,5-a]thieno[3,2-f] [1,4]diazepines as safe anxiolytic agents. Eur. J. Med. Chem. 2020, 200, 112405, https://doi.org/10.1016/j.ejmech.2020.112405.

43. Frydenvang, K.; Pickering, D.S.; Kshirsagar, G.U.; Chemi, G.; Gemma, S.; Sprogøe, D.; Kærn, A.M.; Brogi, S.; Campiani, G.; Butini, S.; Kastrup, J.S. Ionotropic Glutamate Receptor GluA2 in Complex with Bicyclic Pyrimidinedione-Based Compounds: When Small Compound Modifications Have Distinct Effects on Binding Interactions. ACS Chem. Neurosci. 2020, 11, 1791-1800, https://doi.org/10.1021/acschemneuro.0c00195.

44. Gabr, M.T.; Brogi, S. MicroRNA-Based Multitarget Approach for Alzheimer's Disease: Discovery of the First-In-Class Dual Inhibitor of Acetylcholinesterase and MicroRNA-15b Biogenesis. J. Med. Chem. 2020, 63, 9695-9704, https://doi.org/10.1021/acs.jmedchem.0c00756.

45. Saraswati, A.P.; Relitti, N.; Brindisi, M.; Osko, J.D.; Chemi, G.; Federico, S.; Grillo, A.; Brogi, S.; McCabe, N.H.; Turkington, R.C.; Ibrahim, O.; O’Sullivan, J.; Lamponi, S.; Ghanim, M.; Kelly, V.P.; Zisterer, D.; Amet, R.; Hannon Barroeta, P.; Vanni, F.; Ulivieri, C.; Herp, D.; Sarno, F.; Di Costanzo, A.; Saccoccia, F.; Ruberti, G.; Jung, M.; Altucci, L.; Gemma, S.; Butini, S.; Christianson, D.W.; Campiani, G. SpiroindolineCapped Selective HDAC6 Inhibitors: Design, Synthesis, Structural Analysis, and Biological Evaluation. ACS Med. Chem. Lett. 2020, 11, 2268-2276, https://doi.org/10.1021/acsmedchemlett.0c00395.

46. Testai, L.; Piragine, E.; Piano, I.; Flori, L.; Da Pozzo, E.; Miragliotta, V.; Pirone, A.; Citi, V.; Di Cesare Mannelli, L.; Brogi, S.; Carpi, S.; Martelli, A.; Nieri, P.; Martini, C.; Ghelardini, C.; Gargini, C.; Calderone, V. The Citrus Flavonoid Naringenin Protects the Myocardium from Ageing-Dependent Dysfunction: Potential Role of SIRT1. Oxid. Med. Cell. Longev. 2020, 2020, 4650207, https://doi.org/10.1155/2020/4650207.

47. Mulliken, R.S. Electronic Population Analysis on LCAO-MO Molecular Wave Functions. I. The Journal of Chemical Physics 1955, 23, 1833-1840, https://doi.org/10.1063/1.1740588.

48. Gangadharan, R.P.; Krishnan, S.S. Natural Bond Orbital (NBO) Population Analysis of 1-Azanapthalene-8ol. Acta Physica Polonica, A. 2014, 125, https://doi.org/10.12693/APhysPolA.125.18.

49. Pîrnău, A.; Chiş, V.; Szabo, L.; Cozar, O.; Vasilescu, M.; Oniga, O.; Varga, R.A. Experimental and theoretical investigation of 5-para-nitro-benzylidene-thiazolidine-2-thione-4-one molecule. J. Mol. Struct. 2009, 924926, 361-370, https://doi.org/10.1016/j.molstruc.2008.12.044.

50. Dhas, D.A.; Joe, I.H.; Roy, S.D.D.; Freeda, T.H. DFT computations and spectroscopic analysis of a pesticide: Chlorothalonil. Spectrochimica Acta Part A: Molecular and Biomolecular Spectroscopy 2010, 77, 36-44, https://doi.org/10.1016/j.saa.2010.04.020.

51. Fleming, I. Frontier orbitals and organic chemical reactions; Wiley: 1977.

52. Pearson, R.G. Absolute electronegativity and hardness correlated with molecular orbital theory. Proceedings of the National Academy of Sciences 1986, 83, 8440, https://doi.org/10.1073/pnas.83.22.8440.

53. Rajesh, P.; Gunasekaran, S.; Gnanasambandan, T.; Seshadri, S. Molecular structure and vibrational analysis of Trifluoperazine by FT-IR, FT-Raman and UV-Vis spectroscopies combined with DFT calculations. Spectrochimica Acta Part A: Molecular and Biomolecular Spectroscopy 2015, 137, 1184-1193, https://doi.org/10.1016/j.saa.2014.08.100. 
54. Parthasarathi, R.; Padmanabhan, J.; Elango, M.; Subramanian, V.; Chattaraj, P.K. Intermolecular reactivity through the generalized philicity concept. Chem. Phys. Lett. 2004, 394, 225-230, https://doi.org/10.1016/j.cplett.2004.07.002.

55. Parthasarathi, R.; Padmanabhan, J.; Subramanian, V.; Sarkar, U.; Maiti, B.; Chattaraj, P. Toxicity analysis of benzidine through chemical reactivity and selectivity profiles: a DFT approach. Internet Electronic Journal of Molecular Design 2003, 2, 798-813.

56. Pulay, P.; Fogarasi, G.; Pang, F.; Boggs, J.E. Systematic ab initio gradient calculation of molecular geometries, force constants, and dipole moment derivatives. J. Am. Chem. Soc. 1979, 101, 2550-2560, https://doi.org/10.1021/ja00504a009.

57. Avci, D.; Atalay, Y. Theoretical analysis of vibrational spectra and scaling-factor of 2-aryl-1,3,4-oxadiazole derivatives. Int. J. Quantum Chem 2009, 109, 328-341, https://doi.org/10.1002/qua.21789.

58. Silverstein, R.; Bassler, G.; Morrill, T. Spectrometric identification of organic compounds, 1981, 4. New York, John Wiley and Sons.

59. Puviarasan, N.; Arjunan, V.; Mohan, S. FT-IR and FT-Raman studies on 3-aminophthalhydrazide and Naminophthalimide. Turkish Journal of Chemistry 2002, 26, 323-334.

60. Socrates, G. Infrared and Raman characteristic group frequencies: tables and charts; John Wiley \& Sons: 2004.

61. James, C.; Pettit, G.R.; Nielsen, O.F.; Jayakumar, V.S.; Joe, I.H. Vibrational spectra and ab initio molecular orbital calculations of the novel anti-cancer drug combretastatin A-4 prodrug. Spectrochimica Acta Part A: Molecular and Biomolecular Spectroscopy 2008, 70, 1208-1216, https://doi.org/10.1016/j.saa.2007.10.052.

62. Medhi, K.C.; Barman, R.; Sarma, M.K. Vibrational spectra, thermodynamic functions and barrier to internal rotation of 2-chloro-5-nitropyridine. Indian Journal of Physics and Proc of the Indian Assoc for the Cultivation of Science-B 1994, 68, 189-194.

63. Rajamani, T.; Muthu, S.; Karabacak, M. Electronic absorption, vibrational spectra, nonlinear optical properties, NBO analysis and thermodynamic properties of N-(4-nitro-2-phenoxyphenyl) methanesulfonamide molecule by ab initio HF and density functional methods. Spectrochimica Acta Part A: Molecular and Biomolecular Spectroscopy 2013, 108, 186-196, https://doi.org/10.1016/j.saa.2013.01.090.

64. Krishnakumar, V.; Manohar, S.; Nagalakshmi, R. Crystal growth and characterization of Nhydroxyphthalimide (C8H5NO3) crystal. Spectrochimica Acta Part A: Molecular and Biomolecular Spectroscopy 2008, 71, 110-115, https://doi.org/10.1016/j.saa.2007.11.023.

65. Smith, B.C. Infrared Spectral Interpretation: A Systematic Approach; CRC Press: 1998.

66. Abbas, A.; Gökce, H.; Bahçeli, S. Spectroscopic (vibrational, NMR and UV-vis.) and quantum chemical investigations on 4-hexyloxy-3-methoxybenzaldehyde. Spectrochimica Acta Part A: Molecular and Biomolecular Spectroscopy 2016, 152, 596-607, https://doi.org/10.1016/j.saa.2015.01.099.

67. Alegaon, S.G.; Alagawadi, K.R.; Pawar, S.M.; Vinod, D.; Rajput, U. Synthesis, characterization, and biological evaluation of thiazolidine-2,4-dione derivatives. Med. Chem. Res. 2014, 23, 987-994, https://doi.org/10.1007/s00044-013-0705-2. 